\title{
Mediterranean oceanic response to the interannual variability of a high-resolution atmospheric forcing: A focus on the Aegean Sea
}

\author{
A. Bozec, ${ }^{1}$ P. Bouruet-Aubertot, ${ }^{1}$ K. Béranger, ${ }^{2}$ and M. Crépon ${ }^{1}$ \\ Received 1 December 2005; revised 19 July 2006; accepted 27 July 2006; published 25 November 2006.
}

[1] We investigated the interannual variability of the Mediterranean Sea thermohaline circulation under present climate conditions using an oceanic model of $1 / 8^{\circ}$ resolution. Two numerical simulations of 50 year duration were performed. In a control simulation the model was forced by a perpetual year forcing inferred from the climatology of the ECMWF fields, while in a random simulation the 6 years of the ECMWF fields were randomly applied. In this way we were able to test the sensitivity of the thermohaline circulation under an atmospheric interannual variability. In particular, during the last 10 years of the random simulation a succession of cold winters led to anomalous deep water formation in the Aegean Sea. We focused our analysis on this event. This anomalously dense water mostly forms in the Central and Southern Aegean subbasins with a formation rate of about $0.6 \mathrm{~Sv}$. This led to strong modifications in water mass budgets and circulation with intensified exchanges between these two subbasins. The export of those dense waters to the Levantine basin remains weak except for a few particular years. Thus the impact of this event is localized as opposed to the Eastern Mediterranean Transient. These results show the possibility for transient events to reoccur in the Eastern basin in the forthcoming years.

Citation: Bozec, A., P. Bouruet-Aubertot, K. Béranger, and M. Crépon (2006), Mediterranean oceanic response to the interannual variability of a high-resolution atmospheric forcing: A focus on the Aegean Sea, J. Geophys. Res., 111, C11013, doi:10.1029/2005JC003427.

\section{Introduction}

[2] The Mediterranean Sea is a key region regarding climate change. This results from its location at the boundary of two contrasting climates, the European temperate climate and the African tropical climate that makes it especially sensitive to changes. Another interesting feature is that the Mediterranean Sea has its own thermohaline circulation (hereafter THC) which is of a much shorter timescale than that of the global ocean thermohaline circulation. For instance, typical timescales for intermediate and bottom waters renewal are of 25 years and 100 years, respectively [Stratford and Williams, 1997]. Thus any change in deep water formation as well as further evolution of these water masses can be tracked and analyzed over a few decades. These features explain why the Mediterranean Sea is often referred to as a test basin that allows process oriented studies of the low frequency variability of the global thermohaline circulation.

\footnotetext{
${ }^{1}$ Laboratoire d'Océanographie et de Climatologie -Expérimentation et Approches Numériques-, LOCEAN/IPSL/UPMC (previously LODYC), Paris, France.

${ }^{2}$ Unité de Mécanique, Ecole Nationale Supérieure de Techniques Avancées, Paris, France.

Copyright 2006 by the American Geophysical Union. 0148-0227/06/2005JC003427
}

[3] Observations during the last two decades give evidence of an important variability of the thermohaline circulation on shorter timescales. These modifications were noticed in the Aegean Sea. There, particularly strong atmospheric forcing, intense winds and surface cooling, associated with salinity anomalies led to intermediate and deep water formation in the Cretan Sea [Roether et al., 1996]. This anomalous formation of dense waters in turn altered the whole thermohaline cell as reported by Lascaratos et al. [1999]. Indeed these newly formed dense waters then propagated into the Levantine basin and the Ionian basin where they replaced the Eastern Mediterranean Deep Water (EMDW) [Malanotte-Rizzoli et al., 1999]. Meanwhile, a strong decrease of the formation of Adriatic Deep Water was observed [Klein et al., 1999]. This major event is now referred to as the "Eastern Mediterranean Transient" (thereafter EMT) due to the fact that the main formation site of the EMDW shifted from the Adriatic Sea to the Aegean Sea.

[4] Realistic numerical studies were conducted with the aim of reproducing the EMT in order to better understand the physical mechanisms involved [Wu et al., 2000; Demirov and Pinardi, 2002; Stratford and Haines, 2002; Nittis et al., 2003]. Most of these studies used the reanalysis ECMWF (ERA40) of resolution $125 \mathrm{~km}$ to generate the EMT and found that the atmospheric forcing was principally responsible for this event. In particular, Stratford and 
Haines [2002] showed that the succession of three cold winters led to an anomalous event in the Aegean Sea. Later, Nittis et al. [2003] found that these cold winters and the drought that appeared during the EMT period over the Aegean Sea were the main driven mechanisms. The aim of our study is to determine whether such anomalous event could reoccur in the near future and what are the driving mechanisms.

[5] The context of our study lies in between these two frameworks, process-oriented and realistic. Indeed it can be viewed as a process-oriented study since we do not focus on a particular period but rather test the response of the model forced by a realistic atmospheric forcing with a strong interannual variability. Knowing this variability may help to understand the evolution of the THC under future climate conditions. On the other hand the study can be viewed in a more realistic sense since the sensitivity of the response will be focused on the Aegean Sea under anomalous cold conditions, as observed during the EMT. The purpose is thus to test the generality of this kind of anomalous event.

[6] We investigated the variability of the thermohaline circulation using an intermediate resolution oceanic general circulation model, namely $1 / 8^{\circ}$. The model is forced for 50 years with atmospheric forcing of higher spatial resolution $(60 \mathrm{~km})$ than in previous studies $(125 \mathrm{~km})$. However, a high-resolution atmospheric forcing on a 50 year period was not available at this time. We remedied to this point by imposing a random distribution of the different years of the high-resolution ECMWF analysis.

[7] The first part of this paper consists in the validation of the model. Two simulations of 50 year duration are then performed. In the first one the model is forced with a perpetual year forcing while in the second one the 6 years of the ECMWF forcing are randomly applied in order to simulate a present climate interannual variability. The impact of the interannual variability of the forcing on the thermohaline circulation will thus be estimated from the comparison between these two simulations. The comparison between the control simulation and the interannual simulation is analyzed in section 3. An analysis of an anomalous event in the Aegean Sea is conducted in section 4. In the last section, this event is then discussed in respect with our knowledge of the EMT based on both observations and numerical studies.

\section{Ocean Model}

[8] The first stage consisted in the validation of the oceanic model forced by the recent ECMWF analysis. The oceanic model is the $1 / 8^{\circ}$ resolution Mediterranean configuration of the OPA model [Madec et al., 1998], thereafter referenced to as MED8. This configuration was derived from the MED16 configuration of the MERCATOR French project [Drillet et al., 2000; Siefridt et al., 2002; Béranger et al., 2004]. The model domain extends from $29^{\circ} \mathrm{N}$ to $46^{\circ} \mathrm{N}$ in latitude and from $12^{\circ} \mathrm{W}$ to $38^{\circ} \mathrm{E}$ in longitude including part of the Atlantic Ocean (Gulf of Cadiz). The Atlantic and Mediterranean exchanges are modeled by relaxation of salinity and temperature 3D fields toward the climatology of Reynaud et al. [1998], the relaxation coefficient decreasing from the western boundary to the Strait of Gibraltar. The initial temperature and salinity fields in the Mediterranean Sea are derived from the MEDATLAS II monthly climatology [MEDAR/MEDATLAS Group, 2002]. Partial step parameterization for bathymetry modeling has been implemented [Pacanowski and Gnanadesikan, 1998] which greatly improves the circulation. The vertical grid has 43 levels with vertical spacing varying from $6 \mathrm{~m}$ in surface up to around $200 \mathrm{~m}$ in depth. Viscous and diffusive terms are modeled with a Bilaplacian formulation in the horizontal with diffusivity and viscosity coefficients equal to $2.5 \times 10^{10} \mathrm{~m}^{4} \mathrm{~s}^{-1}$. Vertical eddy diffusivity and viscosity are computed from a 1.5 turbulent closure scheme (based on turbulent kinetic energy [Blanke and Delecluse, 1993]) with an initial value of $1 \times 10^{-5} \mathrm{~m}^{2} \mathrm{~s}^{-1}$ for both vertical viscosity and diffusivity. A "Monotonic Upstream-centered Scheme for Conservation Laws" is used as an advection scheme for tracers [Lévy et al., 2001]. Simulations are performed within the rigid-lid approximation.

[9] Wind stress data and air-sea fluxes are provided by the European Centre for Medium-Range Weather Forecasts (ECMWF). The absorbed short wave component of the solar radiation is a function of depth. The net heat flux is modeled at the surface using the correction method [Barnier et al., 1995]. This method combines a climatological record of the atmospheric heat flux and a retroaction term modeled as a relaxation term. In our study, this term includes a variable relaxation coefficient ranging from $-10 \mathrm{~W} \mathrm{~m}^{-2} \mathrm{~K}^{-1}$ in winter to $-40 \mathrm{~W} \mathrm{~m}^{-2} \mathrm{~K}^{-1}$ in summer and relaxes the modeled SST toward the SST of Reynolds [1988]. Freshwater fluxes (evaporation, precipitation, and river runoffs) are applied as a virtual salt flux that includes a constant relaxation term which relaxes the modeled SSS toward the monthly SSS of MEDATLAS with a relaxation time of 3.7 days as done in K. Béranger et al. (Interannual variability of water formation derived from a very high-resolution model of the Mediterranean circulation, submitted to Ocean Dynamics, 2005, hereinafter referred to as Béranger et al., submitted manuscript, 2005). A UNESCO monthly climatology of 31 river runoffs based on the RivDis database is implemented including the Black Sea outflow in the Aegean Sea.

[10] Simulations are started in summer in order to prevent strong mixing at the beginning of the simulation that would modify thermohaline properties of the basin before stabilization. The MEDATLAS II climatology [MEDAR/MEDAT$L A S$ Group, 2002] that takes into account in situ data available since the EMT, is chosen as initial state of the simulation.

[11] High resolution ECMWF atmospheric forcing were available from March 1998 to December 2003. Note that the ECMWF forcing is "extended" from September 1997 to February 1998 using the ERA40 outputs, in order to provide a full sixth year period. Then, two cycles are realized using this forcing leading to 12 years of simulation: MED8-ECMWF. We check that the mean kinetic energy of the model was stabilized after 8 years.

\subsection{Atmospheric Forcing}

[12] A specific feature of the atmospheric circulation over the Mediterranean Sea, related to the complex orography, is the presence of local winds such as the Mistral in the Gulf of Lion or the Etesian winds in the Aegean Sea. The 


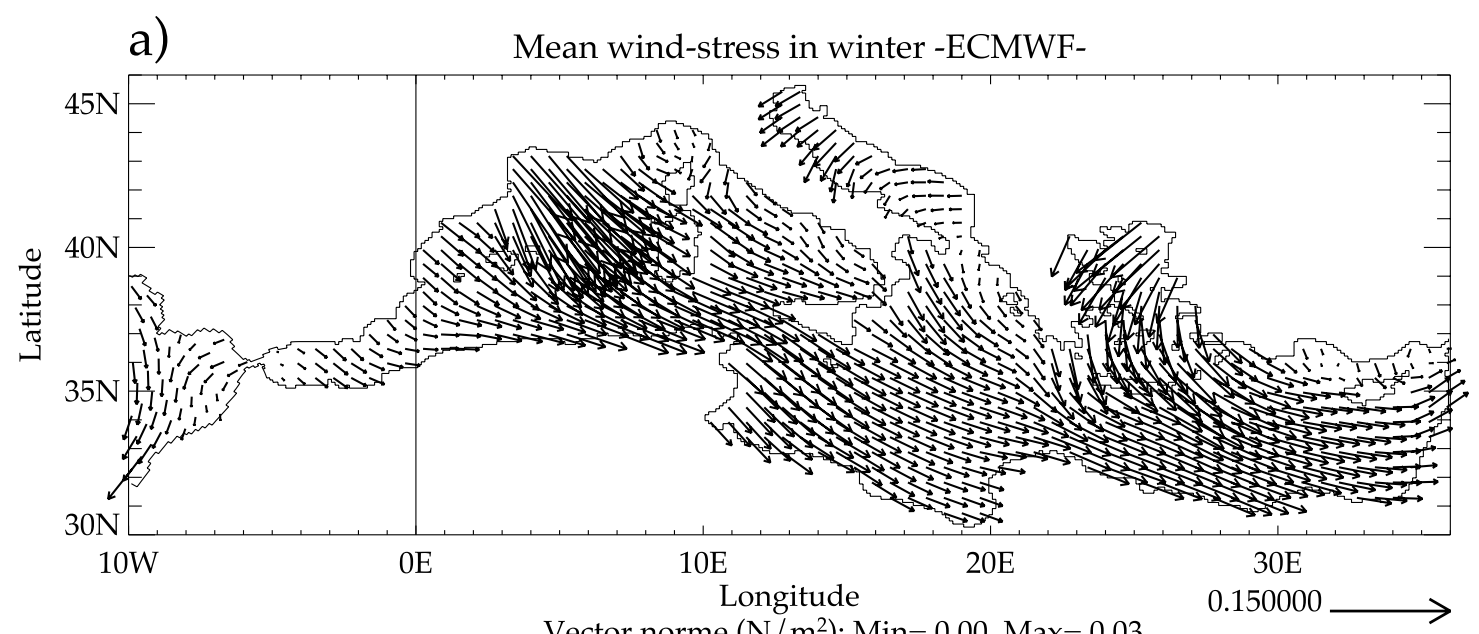

Vector norme $\left(\mathrm{N} / \mathrm{m}^{2}\right)$ : $\mathrm{Min}=0.00, \operatorname{Max}=0.03$

b) Mean heat-flux in winter -ECMWF-
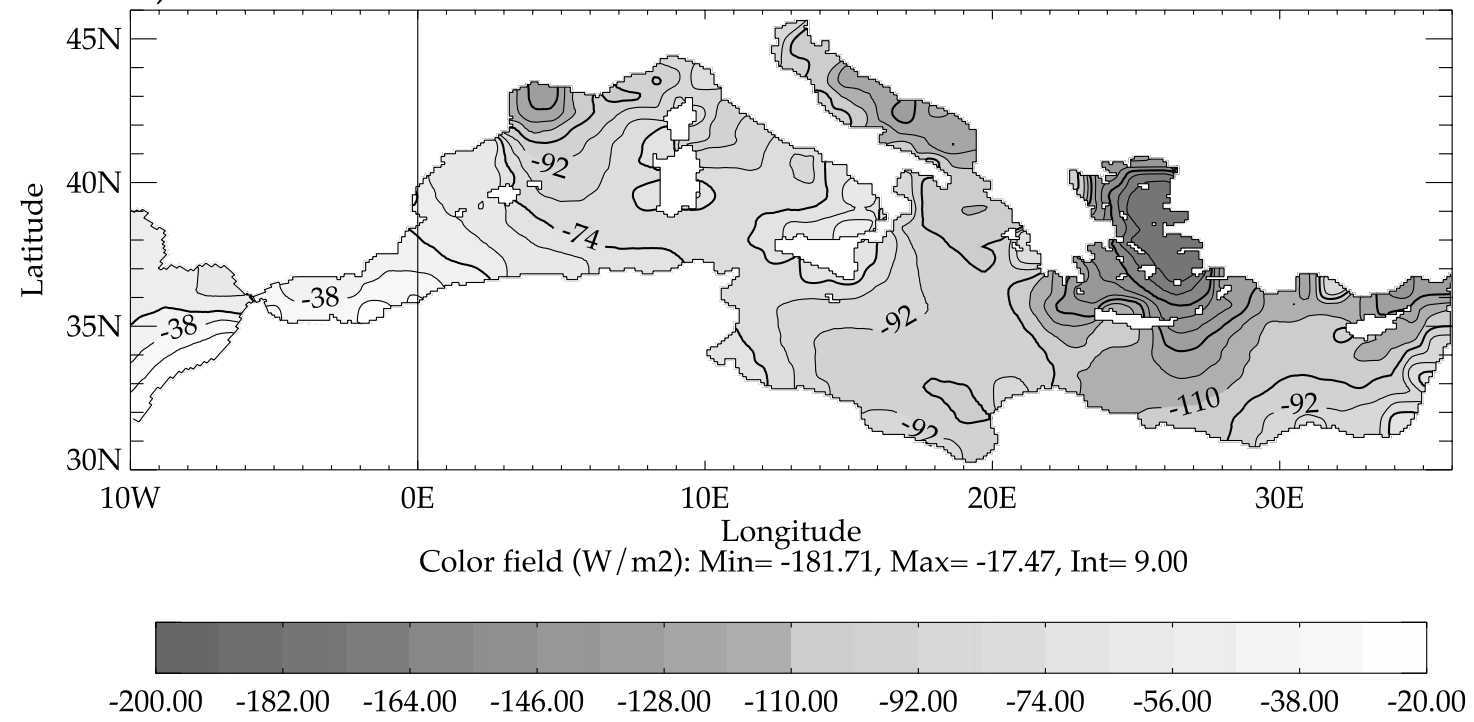

Figure 1. (a) Mean wind stress in winter of the 1998-2003 ECMWF forcing (in $\mathrm{N} / \mathrm{m}^{2}$ ). (b) Mean heat flux in winter of the 1998-2003 ECMWF forcing $\left(\mathrm{W} / \mathrm{m}^{2}\right)$.

outcome is that only a few high-resolution atmospheric models are able to reproduce these local winds [Horton et al., 1994]. These winds are nevertheless of crucial importance regarding water mass formation. Indeed the wind stress has a critical influence on the surface circulation thereby playing a preconditioning role in water mass formation [Myers et al., 1998]. More generally, both local winds and strong heat loss play a major role in deep water formation. The daily high-resolution analysis of the European Centre for Medium-Range Weather Forecasts (ECMWF) $\left(0.5^{\circ} \times 0.5^{\circ}\right.$ real grid scale, i.e. $\left.\sim 60 \mathrm{~km}\right)$, allows a quite realistic representation of local winds. However it only provides data for the period $(1998,2003)$. Another available forcing was the reanalysis ERA40 obtained from a low resolution version of the ECMWF model $(\sim 125 \mathrm{~km})$. As in the ECMWF analysis, atmospheric data are assimilated in the reanalysis but the coarser grid model, is inadequate regarding meso-scale atmospheric structures associated with the orography. On the counterpart a longer time period (1987, 1999), including the EMT period, is available. Béranger et al. (submitted manuscript, 2005) showed that the ERA40 forcing was not able to reproduce deep water formation in the Mediterranean Sea. Therefore, despite a shorter time series, the high-resolution analyses of ECMWF is used to force the ocean model.

[13] We briefly describe in the following the main features of the atmospheric forcing. The averaged wind stress of ECMWF in winter (January-February-March) is displayed in Figure 1a. In the western Mediterranean Sea, local winds such as the Mistral appearing on the Gulf of Lion are well-reproduced. In the eastern Mediterranean Sea, the cold and dry winds flowing from the Northeast landthe Etesian winds - that play a major role, are retrieved. Their cyclonic structure flowing from the Northeast, north of the Aegean Sea and then from the Northwest on the Levantine basin, are well reproduced by ECMWF.

[14] Let us now describe the net heat flux in winter (namely the climatological heat flux plus the retroaction 
Table 1. First Part of the Table: Averages Over the MED8 Domain of the Climatological Heat Flux and Freshwater Flux Over the Period 1997-2003 for ECMWF; Second Part of the Table: Averages Over the MED8 Domain of the Net Heat Flux and EMP Flux Over the Period 1997-2003 for MED8-ECMWF

\begin{tabular}{lcc}
\hline \hline & $\begin{array}{c}\text { Climatological } \\
\text { Heat Flux, W/m }\end{array}$ & $\begin{array}{c}\text { Freshwater } \\
\text { Flux, mm/d }\end{array}$ \\
\hline ECMWF & $-27.4 \pm 121.7$ & $1.58 \pm 0.95$ \\
\hline MED8-ECMWF & Net Heat Flux, W/m & EMP Flux, mm/d \\
\hline \hline
\end{tabular}

term) in Figure 1b. As expected, the net heat flux has minimum values in regions of convection. The winterly averaged net heat loss is of $-110 \mathrm{~W} / \mathrm{m}^{2}$ as observed by Mertens and Schott [1998]. In the Aegean Sea, the region of minimum net heat flux encompasses a larger domain. Indeed this region extends from the Black Sea river mouth to the Rhodes's region. In the Adriatic Sea, the averaged value of the net heat flux is of about $-100 \mathrm{~W} / \mathrm{m}^{2}$ with a minimum above the main gyre of the basin as described by Artegiani et al. [1997].

[15] The averaged net heat flux is equal to $-2.70 \mathrm{~W} / \mathrm{m}^{2}$ (Table 1). This value compares well with observations [Béthoux, 1979; MacDonald et al., 1994] that indicate a heat loss from the Mediterranean Sea to the atmosphere ranged between $-3 \mathrm{~W} / \mathrm{m}^{2}$ and $-7 \mathrm{~W} / \mathrm{m}^{2}$, this loss being compensated by a heat advection through the Strait of Gibraltar. Note that this fairly good agreement partly results from the daily retroaction term included in the model: the averaged climatological heat flux is equal to $-27.4 \mathrm{~W} / \mathrm{m}^{2}$ for ECMWF (see Table 1). However, the EMP flux (corresponding to evaporation minus precipitation minus runoff plus relaxation term), is underestimated by the model. Indeed the averaged values of $0.94 \mathrm{~mm} / \mathrm{d}$ over the Mediterranean Sea is significantly smaller than the $2.5 \mathrm{~mm} / \mathrm{d}$ inferred from observations [Garrett et al., 1993; Boukthir and Barnier, 2000]. (This value does not take into account the runoff that corresponds to about $10 \%$ of evaporation minus precipitation flux.)

\subsection{Mixed Layer Depth}

[16] A current indicator used for estimating the ability of a model to form water masses is the depth of the mixed layer base. Typical mixed layer depths in the different subbasins inferred from observational data are first described. MED8-ECMWF results are then detailed.

[17] The Gulf of Lion is an important site of convection where the Western Mediterranean Deep Water forms. The convection occasionally reaches the bottom, at about $2700 \mathrm{~m}$, and presents a strong interannual variability [MEDOC Group, 1970]. Likewise, in the eastern Mediterranean Sea, there are two main sites of water formation. The first site of formation is the southern Adriatic Sea where the Adriatic Deep Water (ADW) forms with typical mixed layer depth exceeding $1000 \mathrm{~m}$ [Vilibic and Orlic, 2002]. Deep waters are then exported to the Ionian Sea where they sink down to the bottom forming the Eastern Mediterranean Deep Water (EMDW). The second site is the Levantine basin where Levantine Intermediate and Deep Waters (LIW, LDW) form with typical mixed layer depth equal to 400$500 \mathrm{~m}$ and deeper than $1000 \mathrm{~m}$, respectively [Roether et al., 1998; Gertman et al., 1994]. Also in the last 20 years, anomalous deep waters formed in the Aegean Sea propagated to the Levantine basin and replaced the EMDW in the Ionian basin by internal convection [Lascaratos et al., 1999]. According to Theocharis et al. [2002], intermediate and deep waters continued to form in the Southern Aegean (Cretan Sea) between 1000 and $2500 \mathrm{~m}$ since the 1995 event. Surprisingly a weakening in the heat loss as well as in the intensity of the winds were observed in the western Mediterranean Sea during the period of the EMT, which explains the smaller values of the mixed layer depth in the Gulf of Lion.

[18] A snapshot of the mixed layer depth in February of year 12 of MED8-ECMWF is displayed in Figure 2. The mixed-layer base is defined as the depth where the difference in potential density with the surface reaches $0.01 \mathrm{~kg} \mathrm{~m}^{-3}$. A high interannual variability is observed in
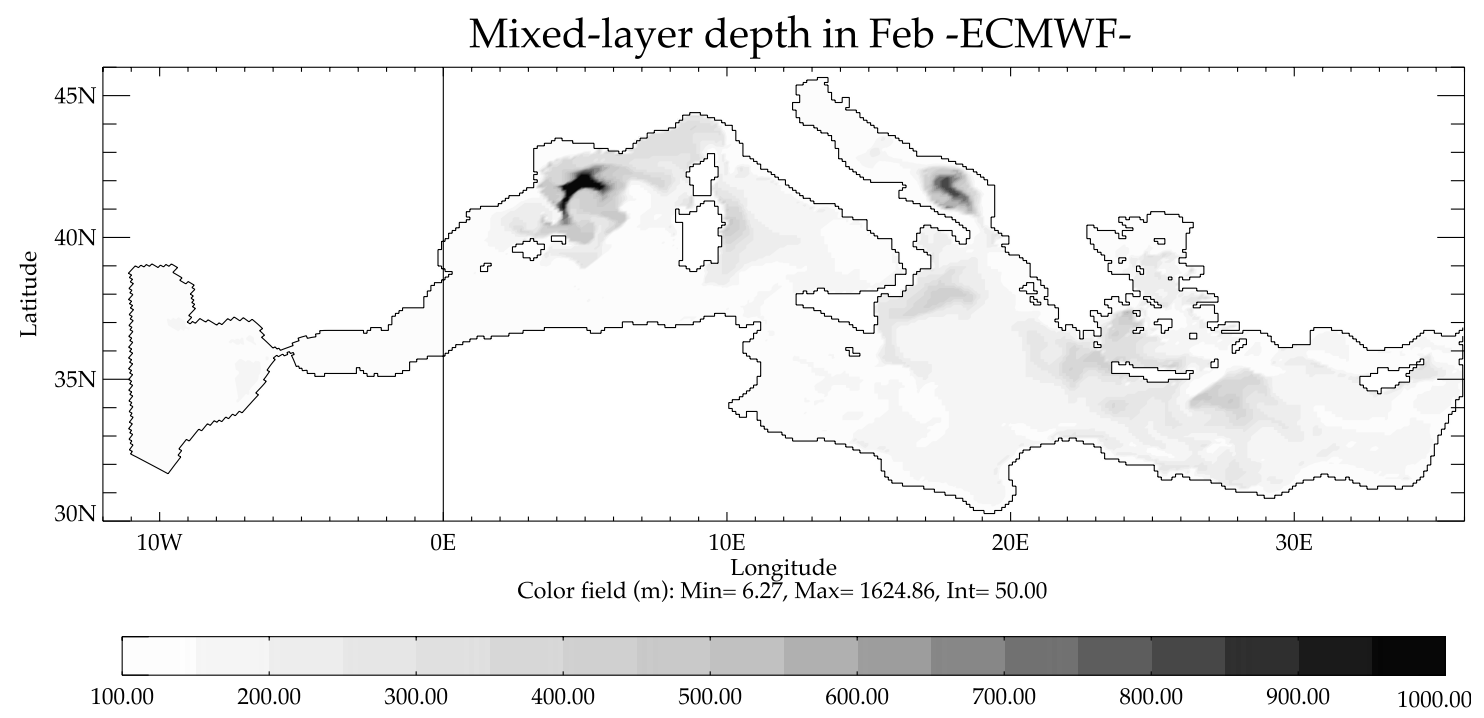

Figure 2. Snapshots of the mixed-layer depth (m) for MED8-ECMWF (year 12). 

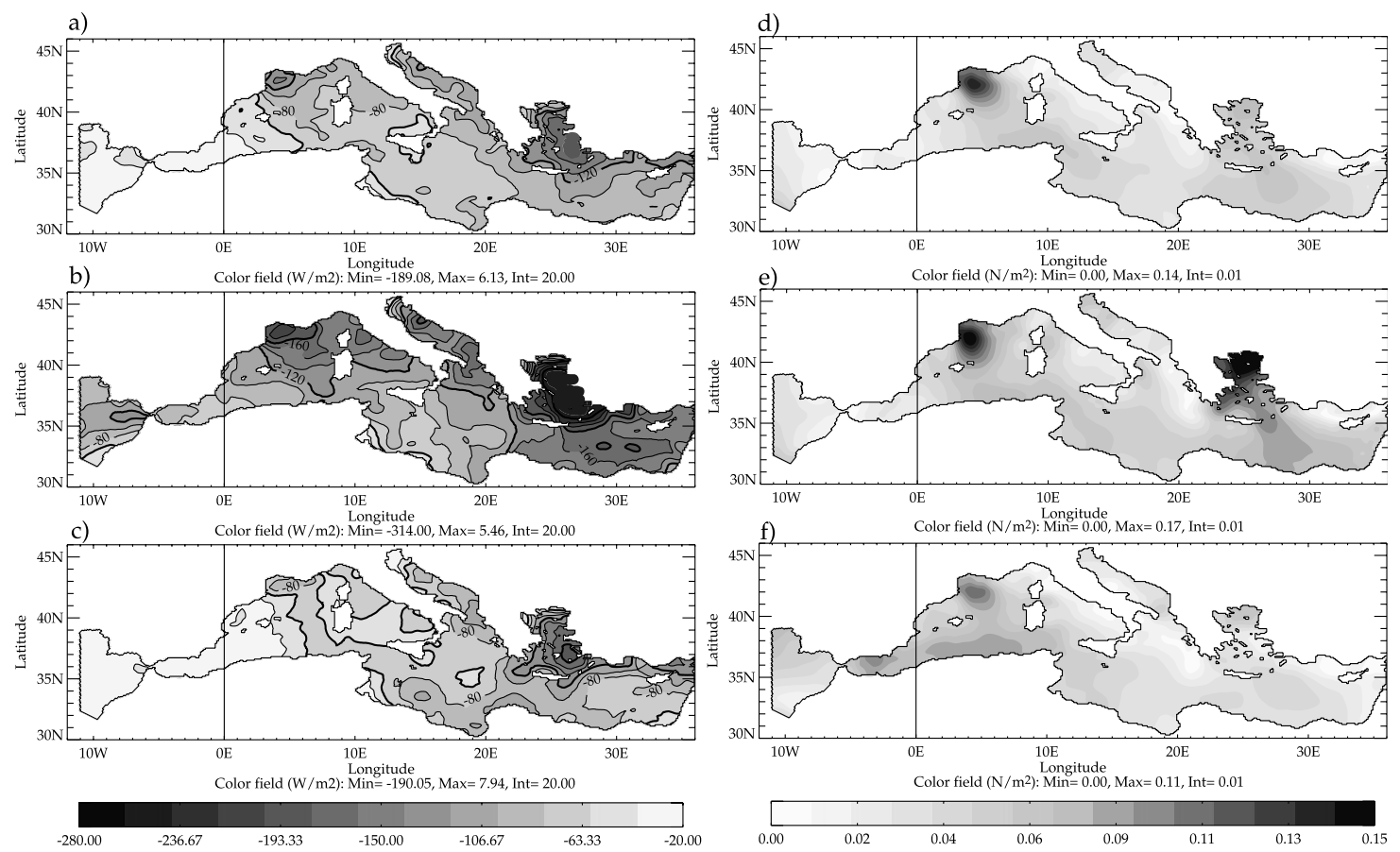

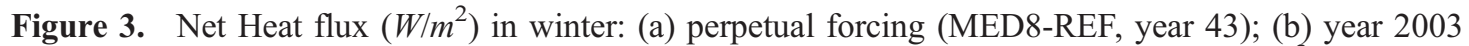
(MED8-RANDOM, year 44); (c) year 2001 (MED8-RANDOM, year 36). Wind stress $\left(\mathrm{N} / \mathrm{m}^{2}\right.$ ) in winter: (d) perpetual forcing; (e) year 2003; (f) year 2001.

the Gulf of Lion (not shown). Convection reaches the bottom of the basin at the beginning of the simulation but the increase in the stratification of the western basin during the simulation inhibits the convection (Figure 2). Note that this bias has also been observed in higher resolution (1/16) simulation performed with MED16 (Béranger et al., submitted manuscript, 2005). Then, typical values of mixed layer depth in the Gulf of Lion are of the order of $800 \mathrm{~m}$.

[19] In the eastern Mediterranean Sea, the simulation reproduces realistic mixed layer depths (Figure 2). In the same way, a strong variability is found in the Levantine basin depending on whether LDW forms (as this is the case during years 7, 9, and 10) in MED8-ECMWF or whether LIW forms (as this is the case for the other years). In the Adriatic Sea, convection extends deeper than $800 \mathrm{~m}$ years 8 and 9 and reaches the bottom year 12. In the Aegean, convection does not occur deeper than $500 \mathrm{~m}$ (Figure 2).

[20] We conclude from this comparison that MED8 forced by ECMWF is able to reproduce realistic water mass formation, especially in the eastern basin. Thus this forcing will be used in the following to study the sensitivity of the Aegean Sea to heat flux anomalies.

\section{The 50-Year Simulations}

[21] Two simulations of 50 years are then performed: MED8-RANDOM is forced by an interannual forcing constructed from ECMWF while MED8-REF is forced by a perpetual forcing. The first 25 years of simulations constitute the spin-up period. The forcing of the control simulation is a perpetual year inferred by averaging the 6 years of ECMWF. The 50 year interannual atmospheric forcing is built by a random function distributing the 6 years of
ECMWF. Each year has been taken the same number of time. We loop a year to another in August when kinetic energy is the weakest. This interannual forcing is characterized by a succession of periods of weak and strong forcing. In particular a series of cold winters over the Aegean Sea occurs during the last 10 years which provides the possibility to test the sensitivity of the Aegean Sea under a strong interannual variability. In this way, we estimate this sensitivity of the Aegean Sea to interannual variability and to a succession of cold winters as performed by Stratford and Haines [2002]. However, the atmospheric analyses period used to force the model is posterior to the EMT period. We here study the possibility of such transient event to reoccur.

\subsection{Characterization of the Atmospheric Forcing of MED8-REF and MED8-RANDOM}

\subsubsection{Winter Situations in MED8-REF and MED8-RANDOM}

[22] The interannual variability of the 6 year ECMWF forcing is illustrated (Figure 3) by winter maps of the net heat flux and wind stress corresponding to the perpetual year (Figures 3a and 3d), the coldest year of the period (2003, Figures $3 \mathrm{~b}$ and $3 \mathrm{e}$ ), and the warmest year of the period (2001, Figures 3c and 3f). During the winter 2003, strong heat loss and intense evaporation are observed in conjunction with strong winds. Comparison with the perpetual winter shows that the main discrepancies are located in the Aegean Sea where the heat loss can reach $300 \mathrm{~W} / \mathrm{m}^{2}$ (Figure $3 \mathrm{~b}$ ) in contrast with the maximum value of $190 \mathrm{~W} / \mathrm{m}^{2}$ for the perpetual year (Figure 3a). This maximum heat loss is reached in the Central and Northern Aegean subbasins, near the Black Sea mouth. The heat loss is still 
a)
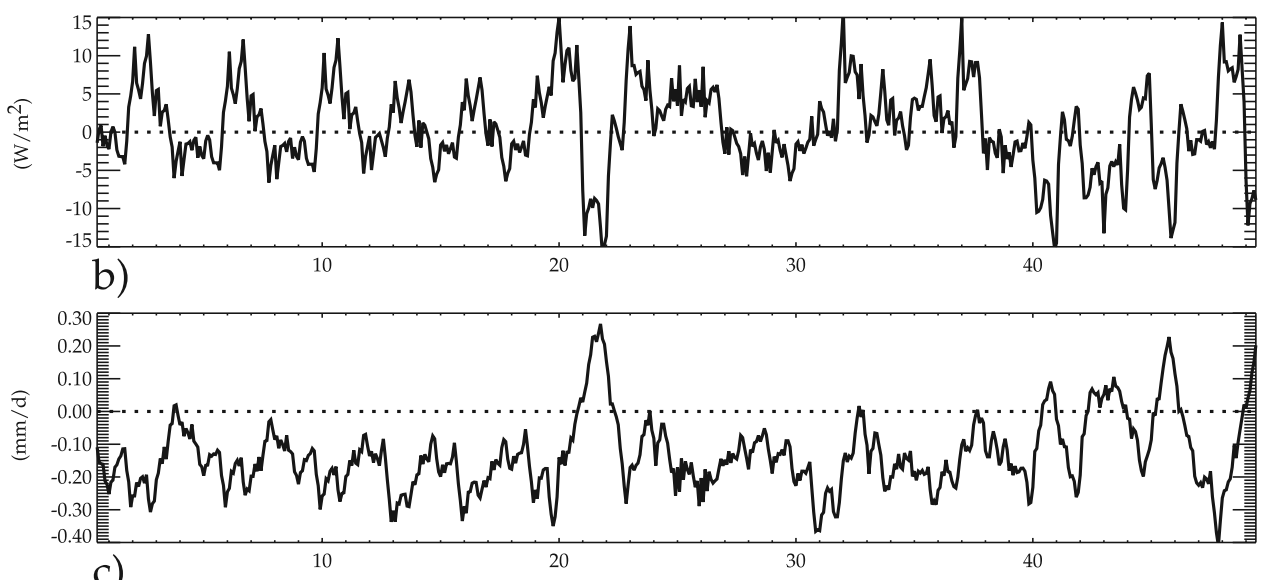

c)

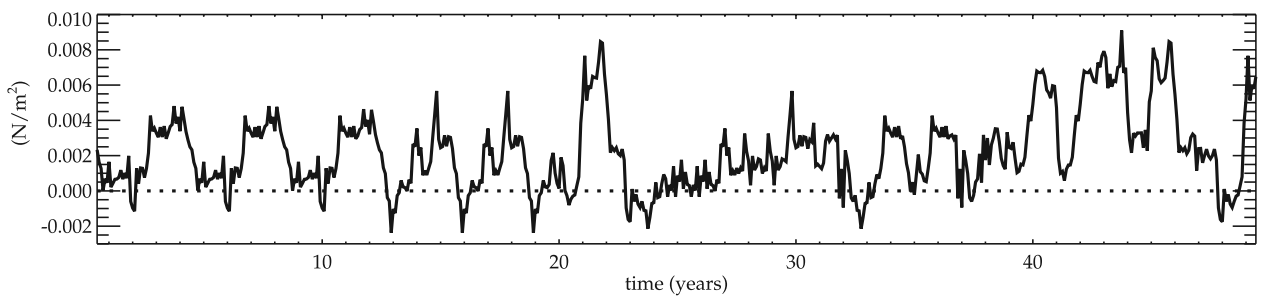

Figure 4. Anomalies between MED8-RANDOM and MED8-REF. Time evolution of the 12 month smoothing anomalies of (a) net heat flux; (b) EMP flux; (c) wind stress modulus.

significant in the Southern Aegean subbasin, the difference when compared with the perpetual year being equal to $160 \mathrm{~W} / \mathrm{m}^{2}$. In other regions such as the Adriatic Sea and the Gulf of Lion, the heat loss is also larger than in the climatology.

[23] Wind stress patterns are similar in all cases. The intensity of the wind is greatly intensified in most regions of the Mediterranean Sea, especially in the Liguro-provenal basin and in the Aegean Sea, with strong Etesian winds. This intensification of the wind stress combined with anomalously strong heat loss will have a significant impact on water mass formation, as analyzed below.

\subsubsection{Interannual Variability of MED8-RANDOM} Forcing

[24] Net heat flux and EMP flux averaged over the 50 years are close to those found in section wind, with an averaged net heat loss of about $-3 \mathrm{~W} / \mathrm{m}^{2}$ and an averaged EMP of $1 \mathrm{~mm} \mathrm{~d}^{-1}$ (Table 2). An overview of the variability of the interannual atmospheric forcing is provided in Figure 4 where the temporal evolution of net heat flux anomalies, EMP flux anomalies and wind stress anomalies are displayed. Note that a 12 month moving average is performed for clarity. The averaged net heat flux anomalies are positive $\left(+0.44 \mathrm{~W} / \mathrm{m}^{2}\right)$ and averaged EMP flux anomalies have a negative bias of $0.13 \mathrm{~mm} \mathrm{~d}^{-1}$ with a variability between $-1.3 \mathrm{~mm} \mathrm{~d}^{-1}$ and $+0.8 \mathrm{~mm} \mathrm{~d}^{-1}$. (Figures $4 \mathrm{a}$ and $4 \mathrm{~b})$. More precisely the temporal evolution gives evidence of an alternation of "weak" and "strong" forcing periods. Two main events are worthwhile to mention: a strong negative net heat flux anomaly associated with a strong positive EMP flux anomaly is observed, firstly in the early twenties, secondly during the last 10 years of the simulation. Most of these anomalies are induced by the cold winter 2003 that occurs on years 20, 40, 42, 43, 45 and 49 in the MED8-RANDOM simulation. Meanwhile, positive wind stress anomalies occur especially during years 43 to 46 (Figure 4c).

\subsection{Overview of the MED8-REF and MED8-RANDOM Simulations}

\subsubsection{Thermohaline Properties}

[25] The anomalies of the basin averaged temperature and salinity as well as the anomalies in the surface forcing are represented in Figure 5. Comparison between Figures 5d and $5 \mathrm{e}$ reveals the good corrrelation between net heat flux anomalies and temperature anomalies. The averaged salinity anomalies are always negative as a result of the negative EMP flux anomalies in MED8-RANDOM compared to MED8-REF while temperature anomalies are mostly positive resulting from positive mean net heat flux anomaly. Further investigation on the time evolution of salinity anomalies shows a decrease during the first 20 years after which the evolution is reversed with a net increase until year 40. A slight decrease is eventually obtained. This evolution can be closely related to that of the EMP flux anomalies (Figure 5f): the strong net evaporation observed around year 20 is responsible for the stabilization of the salinity anomalies while the final decrease in salinity anomalies at the end of the simulation results from strong

Table 2. Net Heat Flux and EMP Flux Averages Over the MED8 Domain for MED8-RANDOM and MED8-REF

\begin{tabular}{lcc}
\hline & Net Heat Flux, W/m & \\
\hline MED8-RANDOM & $-3.16 \pm 130.0$ & EMP Flux, mm/d \\
MED8-REF & $-3.65 \pm 125.0$ & $1.01 \pm 1.31$ \\
\hline
\end{tabular}


a)

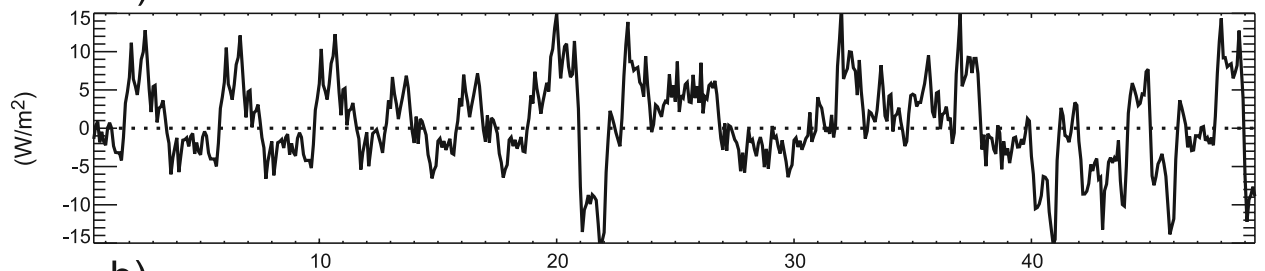

b)

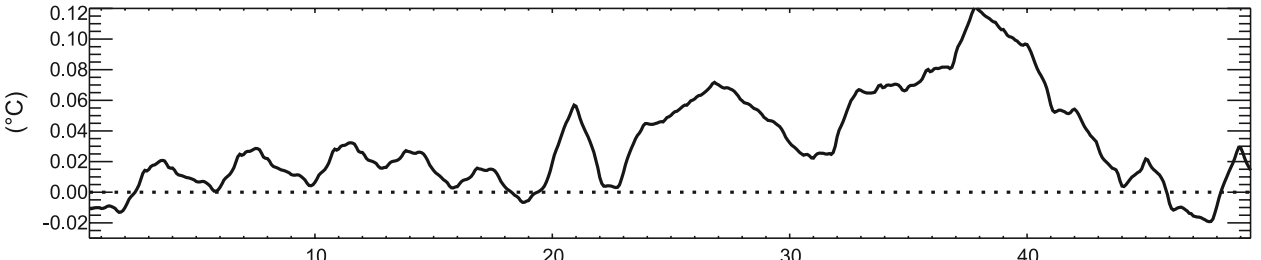

c)

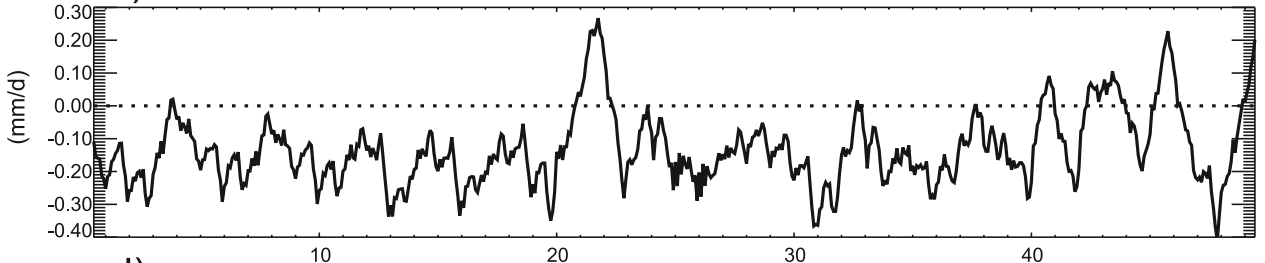

d)

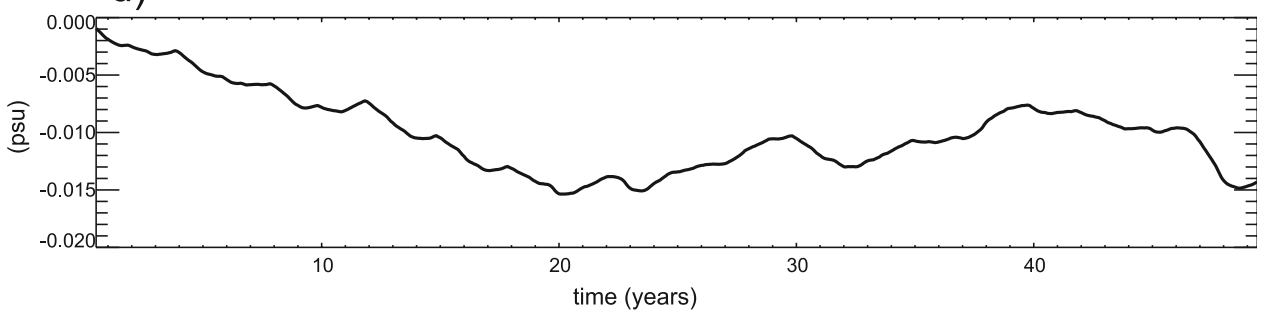

Figure 5. As in Figure 4 for (a) the net heat flux; (b) the temperature; (c) the EMP flux; (d) the salinity.

increase in the EMP flux. The time evolution of temperature anomalies is closely related to that of the net heat flux anomalies, the most striking feature being the strong decrease during the cold period over the last 10 years.

[26] The same analysis of temperature and salinity evolution in the different subbasins reveals that the Levantine basin and the Aegean Sea are mainly responsible for the increase in salinity (from year 20) and for the brutal decrease in temperature during the last decade. Indeed, the salinity increase can be related to the increase in EMP flux over the Levantine basin during this period. In the same way, the succession of cold winters during the last decade of RANDOM leads to a strong decrease in temperature in the Aegean Sea while salinity remains almost constant as detailed in section 4.1.

\subsubsection{Water Mass Formation}

[27] Water mass formation is inferred from the surface density flux, using the diagnosis developed by Walin [1982] and later applied to the Mediterranean Sea by Tziperman and Speer [1994]. In addition the effect of the penetrative solar flux in the oceanic surface layer is taken into account as described by A. Bozec et al. (Impact of penetrative solar flux on water mass transformation in the Mediterranean Sea, submitted to Deep Sea Research, Part I, 2005). The expression for the volume flux through a water mass of density ranging between $\rho$ and $\rho+\Delta \rho$ averaged over a time interval $N \Delta t$ is given by ( $\Pi$ corresponding to the top-hat function):

$$
\begin{aligned}
F(\rho)= & \frac{1}{N \Delta t} \sum_{n=1}^{N} \Delta t \sum_{i, j} \Delta x \Delta y\left[-\frac{\alpha}{C_{p}} Q_{n s o l}+\beta S * E M P\right] \\
& \cdot \Pi(\rho, \rho+\Delta \rho)+\frac{1}{N \Delta t} \sum_{n=1}^{N} \Delta t \sum_{i, j, k} \Delta x \Delta y \Delta z \\
& \cdot\left[-\frac{\alpha}{C_{p}} \cdot \frac{d I_{s o l}}{d z}\right] \Pi(\rho, \rho+\Delta \rho)
\end{aligned}
$$

with $I_{\text {sol }}$ and $Q_{n s o l}$, being solar and nonsolar flux in W.m ${ }^{-2}$, EMP flux (evaporation - precipitation - runoff + relaxation (in $\mathrm{kg} \mathrm{m}^{-2} \mathrm{~s}^{-1}$ )), $\Delta \rho=0.12 \mathrm{~kg} \mathrm{~m}^{-3}, \mathrm{~S}$ the surface salinity (in psu), $C_{p}$ the specific heat (equal to $4000 \mathrm{~J} \mathrm{~kg}^{-1}{ }^{\circ} \mathrm{C}^{-1}$ ), the thermal expansion coefficient $\alpha=-\frac{1}{\rho_{0}} \frac{\partial \rho}{\partial T}$ and the saline contraction coefficient $\beta=\frac{1}{\rho_{0}} \frac{\partial \rho}{\partial S}$. $\Delta x \times{ }^{\rho_{0}} \Delta y \times \Delta z$ is the volume of a grid cell. The function $I_{\text {sol }}(z)=I_{0}\left[R e^{-\frac{z}{\xi_{1}}}+(1-R)\right.$ $\left.e^{-\frac{z}{\xi_{2}}}\right]$ is a spectral parameterization of the penetrative solar radiation, corresponding to a Type I water in Jerlov's [1968] classification: $\xi_{1}=0.35 \mathrm{~m}, \xi_{2}=23 \mathrm{~m}$ and $\mathrm{R}=0.58 . I_{0}$ is the solar radiation flux across the sea surface.

[28] This formulation is applied to the different basins of convection, namely the Gulf of Lion, the Adriatic Sea, the 
a)

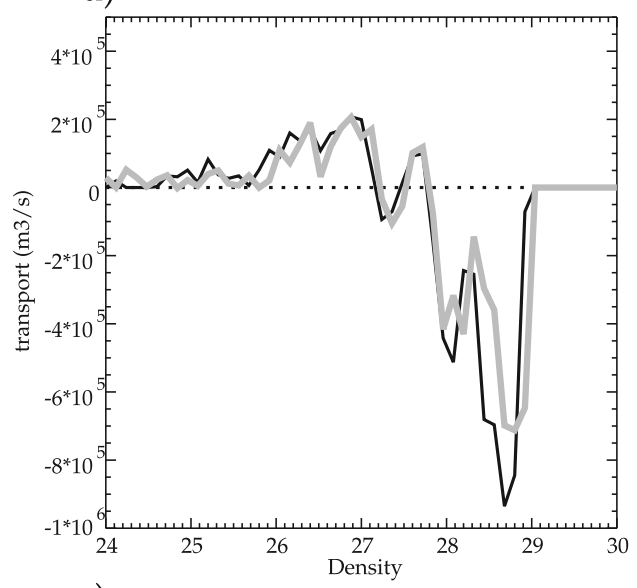

c)

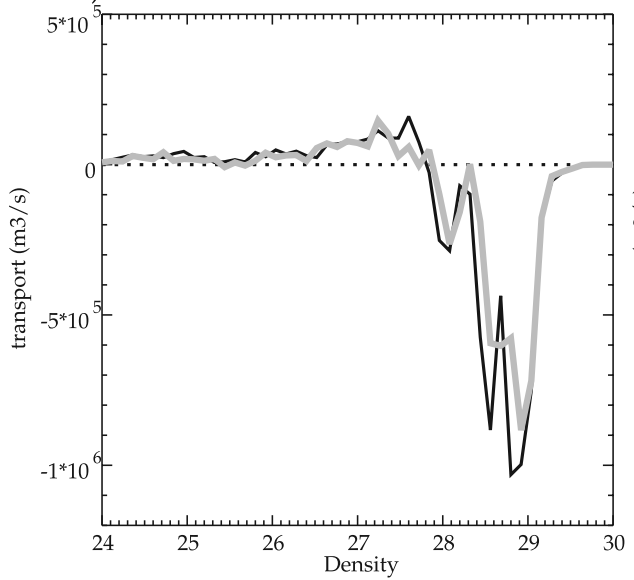

b)

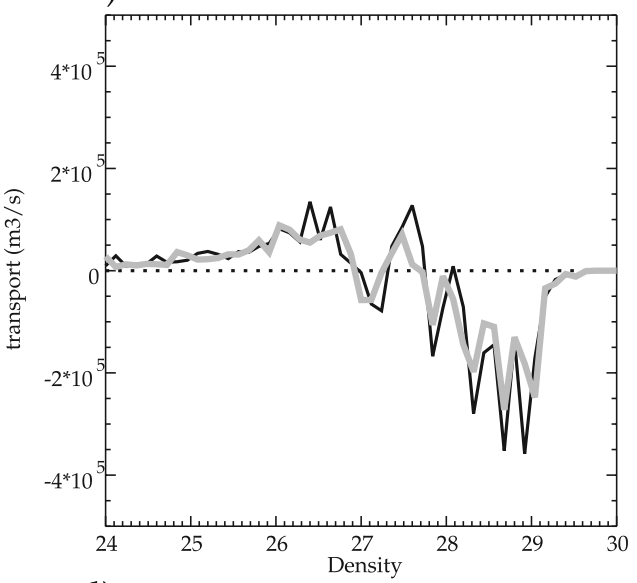

d)

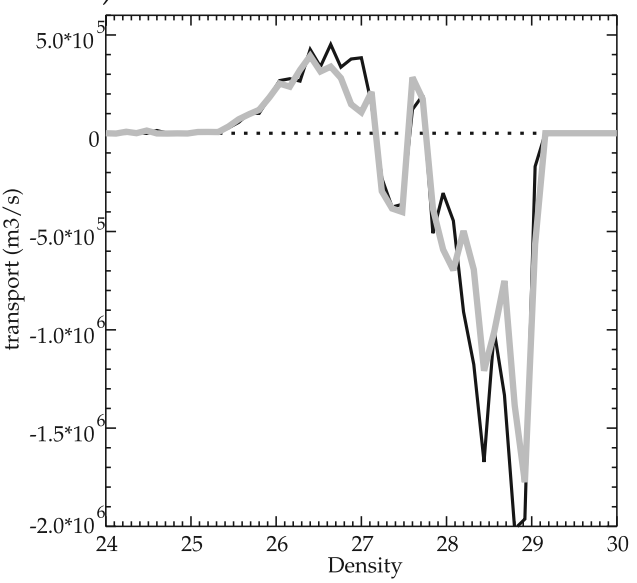

Figure 6. Water mass transformation during the last 10 years of the simulations: (a) in the Gulf of Lion; (b) in the Adriatic Sea; (c) in the Aegean Sea; (d) in the Levantine basin. Results for MED8-RANDOM are represented in black and those of MED8-REF in grey.

Aegean Sea and the Levantine basin. Results are shown for the last 10 years of the simulation to give evidence of the effect of the cold forcing period of the MED8-RANDOM simulation (Figure 6).

[29] Transformation rates are displayed in Figure 6. Similar shapes are obtained for MED8-REF and MED8RANDOM. The main difference arises for dense waters, of potential density higher than $\sigma_{\theta}=28 \mathrm{~kg} \mathrm{~m}^{-3}$, whose formation rate is increased when the random forcing is applied. Indeed, the averaged increase in formation rate is of about $30 \%$ for all subbasins. In addition the density of the minimum peak is slightly shifted toward smaller values in MED8-RANDOM due to the increase in the averaged temperature and to the decrease in the averaged salinity in this simulation. This shift in density can reach about $+0.15 \mathrm{~kg} \mathrm{~m}^{-3}$ as obtained in the Gulf of Lion (Figure 6a). The other difference arising when random forcing is applied, is a more important destruction of mid-density waters within the range $\sigma_{\theta}=\left[27.2 \mathrm{~kg} \mathrm{~m}^{-3}, 27.9 \mathrm{~kg} \mathrm{~m}^{-3}\right]$ in the Aegean Sea (Figure $6 \mathrm{c}$ ) and $\sigma_{\theta}=\left[26.7 \mathrm{~kg} \mathrm{~m}^{-3}, 27.4 \mathrm{~kg} \mathrm{~m}^{-3}\right]$ in the Levantine basin (Figure 6d) in MED8-REF.

[30] The MED8-RANDOM forcing thus leads to an enhancement of the formation of dense waters as a result of the occurrence of extreme forcing such as that of winter 2003. This impact is especially significant in the Aegean Sea during the last ten years of MED8-RANDOM and is the subject of the next section.

\section{Anomalous Event in the Aegean Sea in MED8-RANDOM}

4.1. Overview of the Atmospheric Forcing and Evolution of Thermohaline Properties

[31] The evolution of the surface forcing and of the water mass characteristics of the Aegean Sea is given in Figure 7. The period of particular interest is indicated by the two vertical lines shown in Figure 7, between year 39 and year 47 . We denote a high variability of the net heat flux anomalies over the Aegean Sea. Values of the net heat flux are ranging between $-200 \mathrm{~W} / \mathrm{m}^{2}$ and $100 \mathrm{~W} / \mathrm{m}^{2}$. Periods of enhanced heat loss are more frequent during the last decade of the simulation and correspond to a succession of winter 2003 as underlined before. This intense heat loss leads to a strong decrease of the basin averaged temperature of about $0.7^{\circ} \mathrm{C}$ in 8 years (Figures $7 \mathrm{a}$ and $7 \mathrm{c}$ ). Then, temperature increases again from year 47 to the end of the simulation as a result of moderate heat loss. 
a) Aegean Sea Net Heat Flux

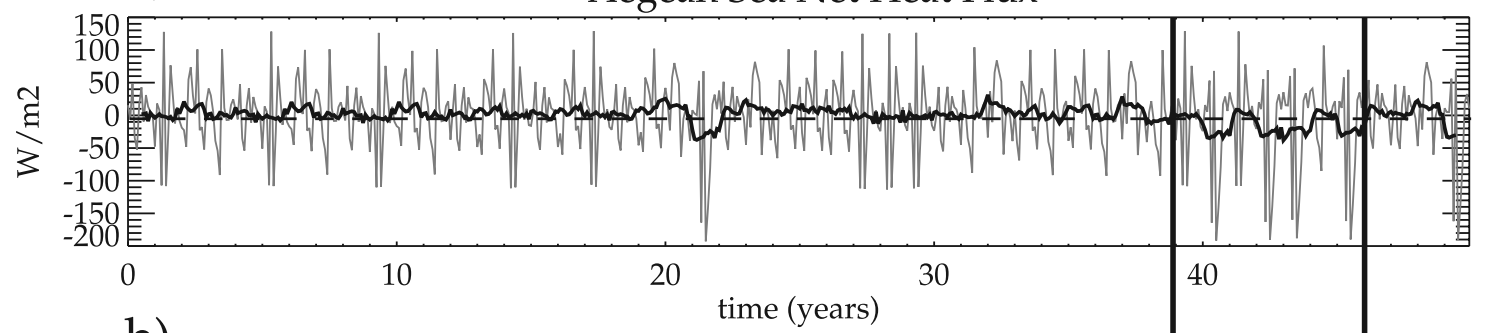

b)
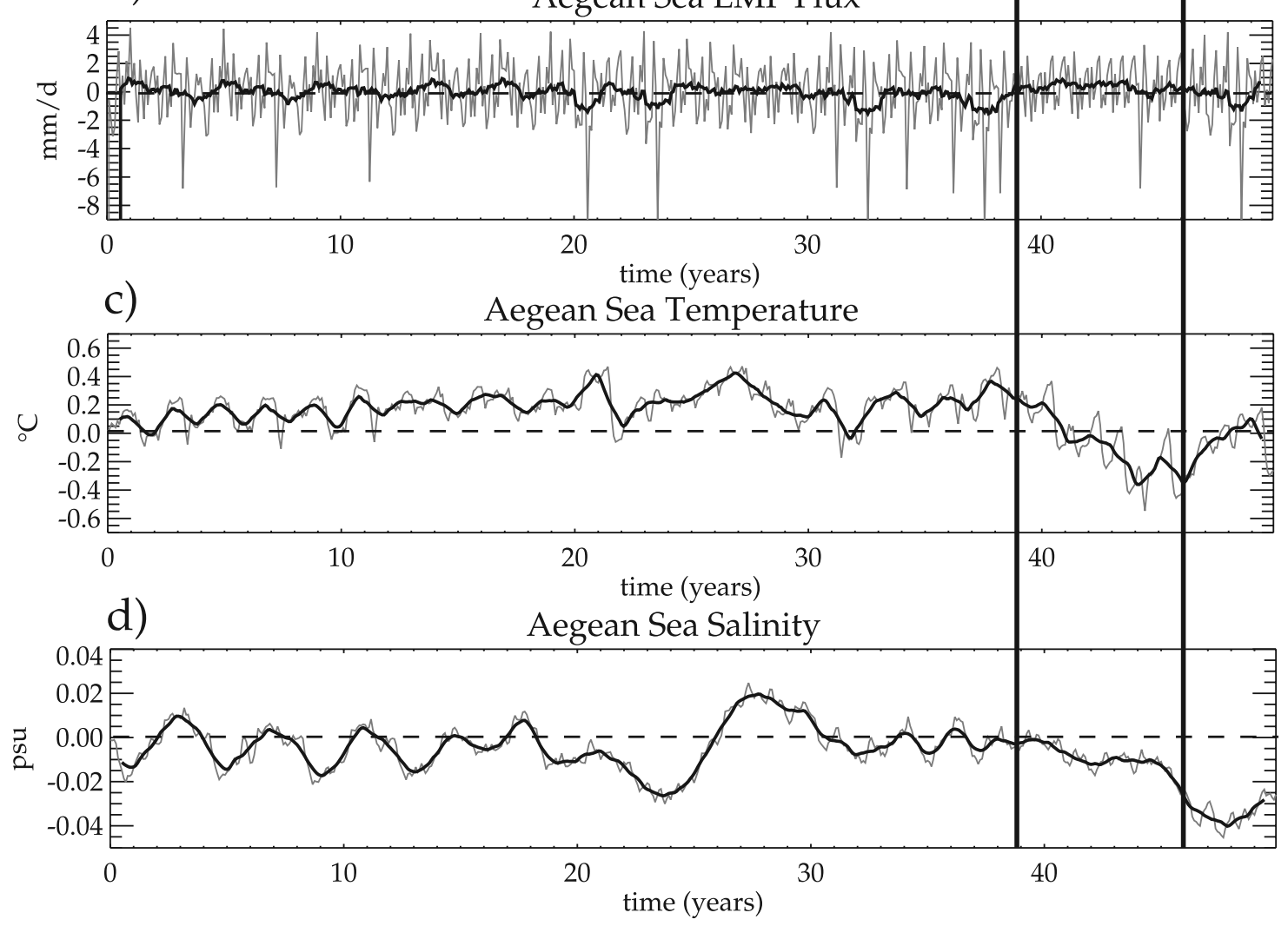

Figure 7. Time evolution of the anomalies averaged over the Aegean Sea of (a) the net heat flux, (b) the EMP flux, (c) the temperature, and (d) the salinity for MED8-RANDOM. Thin black lines are monthly value, and thick black lines correspond to a 12 -month smoothing.

[32] The time evolution of the EMP flux is fairly smooth when a 12 year moving average is applied. However a monthly moving average reveals the occurrence of negative peaks between -8 and $-6 \mathrm{~mm} \mathrm{~d}^{-1}$ during summer 20, 23, 32 and 37 (corresponding to ECMWF summer 1998) and summer 3, 7, 11, 31, 34, 36, 38 and 44 (corresponding to ECMWF summer 2001). It is quite likely that the weak EMP flux has a preconditionning role in the salinity decrease that is observed during the anomalous event.

\subsection{Convection in the Aegean Sea}

[33] The abnormal cold atmospheric forcing triggers an increase in density of surface waters leading to anomalously dense water formation in the Aegean Sea. Note that the Aegean Sea rapidly responds to this atmospheric forcing. This can be related to its geographical situation and the relative shallowness of this subbasin compared with the rest of the basin. We focus here on the early stage of the development of this anomalous event, namely year 45 of
MED8-RANDOM. Horizontal and vertical sections across the Aegean Sea, displayed in Figure 8, enlighten the strong changes in water masses. In particular horizontal sections of the density fields at $292 \mathrm{~m}$ depth (Figures 8a and 8c) reveal that the largest increase in potential density takes place in the Central Aegean Sea with a value of the order of $0.2 \mathrm{~kg} \mathrm{~m}^{-3}$. Vertical sections displayed in Figures $8 \mathrm{~b}$ and $8 \mathrm{~d}$ along $25.55^{\circ} \mathrm{E}$ show the complete vertical extension of these anomalies. Indeed, density is increased over the whole water column, with maximum density value of $\sigma_{\theta}=$ $29.35 \mathrm{~kg} \mathrm{~m}^{-3}$ in MED8-RANDOM, to be compared with the $\sigma_{\theta}=29.15 \mathrm{~kg} \mathrm{~m}^{-3}$ maximum value in MED8-REF. Part of this newly formed water mass flows into the Southern Aegean subbasin along the Greek coast (Figure 8c). Note that convection also occurs in the Southern subbasin but the density of the water formed is significantly smaller than that of the Central subbasin, with values equal to $29.1 \mathrm{~kg} \mathrm{~m}^{-3}$ in MED8-RANDOM and to $29.05 \mathrm{~kg} \mathrm{~m}^{-3}$ in MED8-REF. 


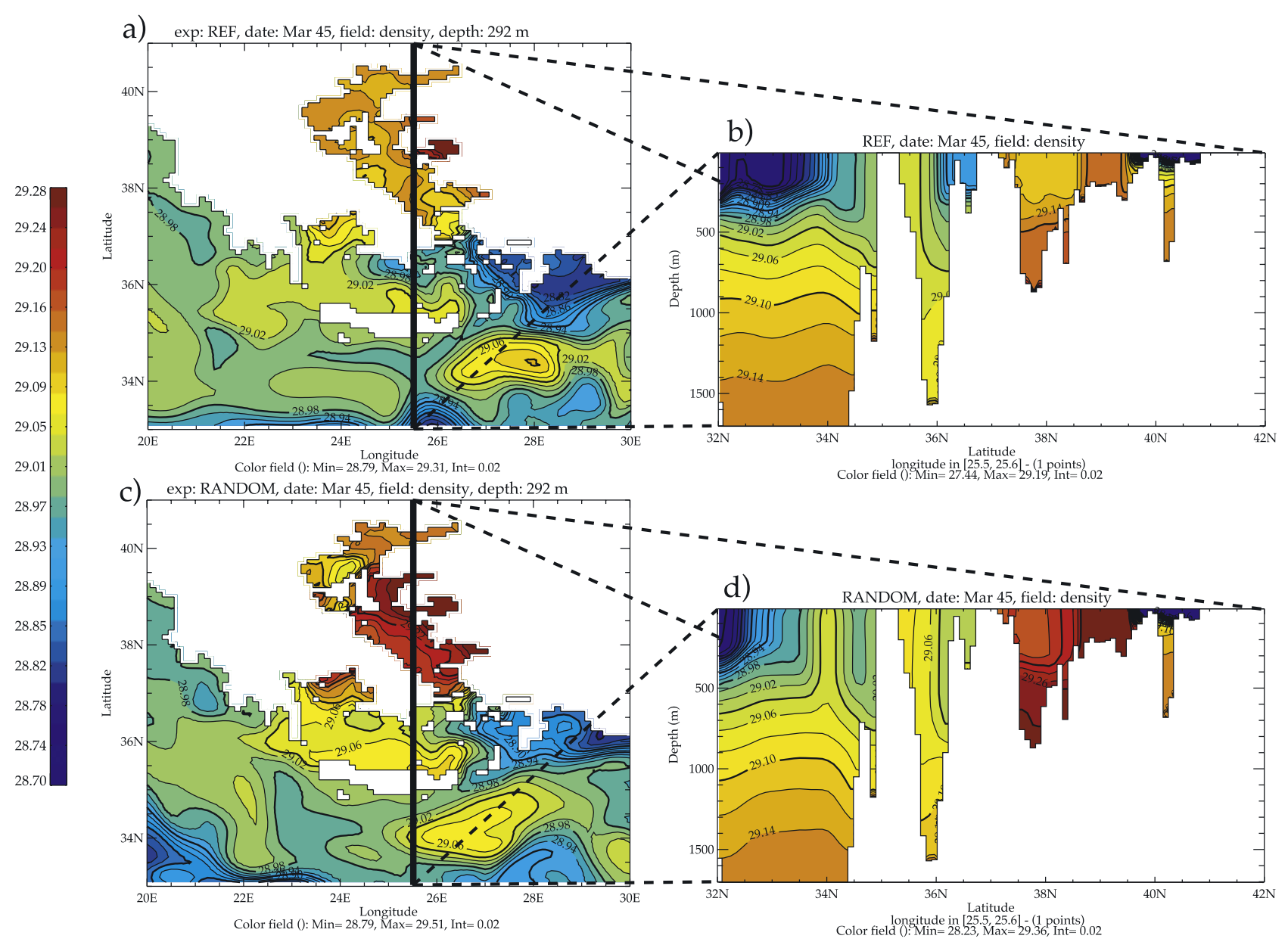

Figure 8. Potential density during March of year 45 in MED8-RANDOM and MED8-REF: (a) density at depth $292 \mathrm{~m}$ in MED8-REF, (b) meridional section of density at $25.55^{\circ} \mathrm{E}$ in MED8-REF, (c) density at depth $292 \mathrm{~m}$ in MED8-RANDOM, and (d) meridional section of density at $25.55^{\circ} \mathrm{E}$ in MED8RANDOM.

[34] Meridional sections through the Aegean Sea account for the division of this region into three subbasins: the Northern Aegean subbasin $\left(39^{\circ} \mathrm{N}-42^{\circ} \mathrm{N}\right)$, the Central Aegean subbasin $\left(37^{\circ} \mathrm{N}-39^{\circ} \mathrm{N}\right)$ and the Southern Aegean subbasin, the so-called Cretan Sea $\left(35^{\circ} \mathrm{N}-37^{\circ} \mathrm{N}\right)$, as done in Nittis et al. [2003] (Figure 9a). Hence water mass budgets are established in these three subbasins in order to analyze the spatio-temporal evolution of the anomalous event.

\subsection{Water Masses in the Aegean Sea}

[35] The thermohaline properties of water masses of the three Aegean subbasins in winter are summarized in Figure 10. This representation underlines the contrasting thermohaline properties of these subbasins. In the Northern subbasin, waters are comparatively cold and fresh due to the combined action of the Etesian winds in winter, cooling surface waters, and of the Black Sea discharge. In contrast, surface and intermediate waters in the Southern subbasin are comparatively warm and salty due to the strong evaporation and to the inflow of waters originating from the Levantine basin and flowing through the straits of Kassos and Karpathos. In between, water masses of the Central Aegean subbasin have intermediate properties.
[36] Evidence of the major changes that have occurred during the last 10 years of the simulation in the Aegean Sea is given in Figure 10 where $\theta-S$ plots are displayed over a 10 year period before the event (years 25-35) and over the last 10 years of the simulation including the anomalous period (years 39-50).

[37] The major change is the formation of a new water mass during the last decade of MED8-RANDOM (in the Central subbasin, Figures 10c and 10d). This formation results from a decrease in temperature of about $0.5^{\circ} \mathrm{C}$ of deep waters that were previously distributed within the temperature range $14-15^{\circ} \mathrm{C}$ and within the salinity range $38.8-39$ psu. These waters then reach the highest density of the Aegean Sea with a potential density value equal to $29.3 \mathrm{~kg} \mathrm{~m}^{-3}$ (Figure 10d).

[38] In contrast, the $\theta-S$ diagrams are almost similar in the Northern subbasin (Figures 10a and 10b). The only difference is observed for intermediate and bottom waters that become slightly denser, as in the Central subbasin, with a maximum density value equal to $29.25 \mathrm{~kg} \mathrm{~m}^{-3}$. Note that this increase in density mostly results from a temperature decrease of about $\left(-0.5^{\circ} \mathrm{C}\right)$. 
a)

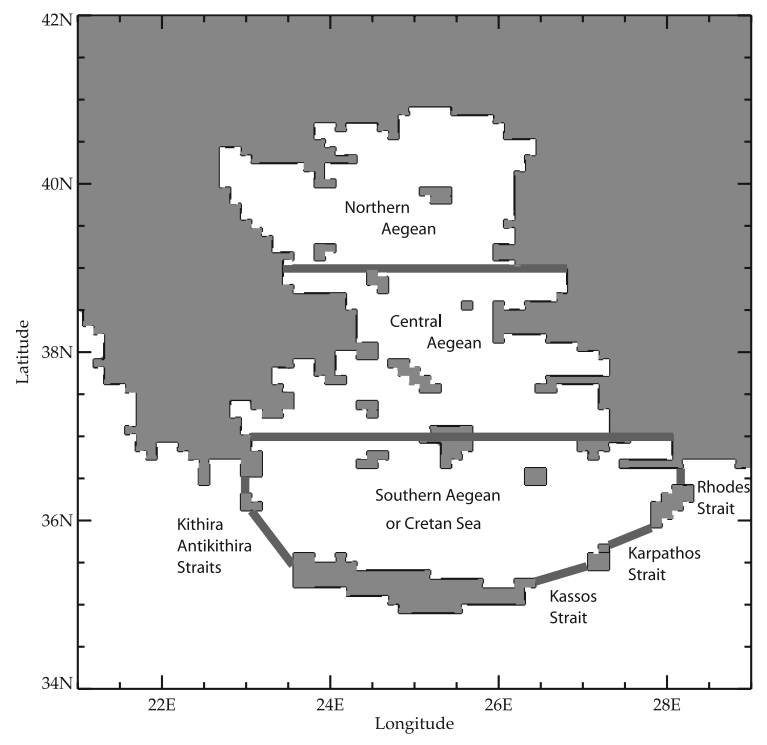

b)

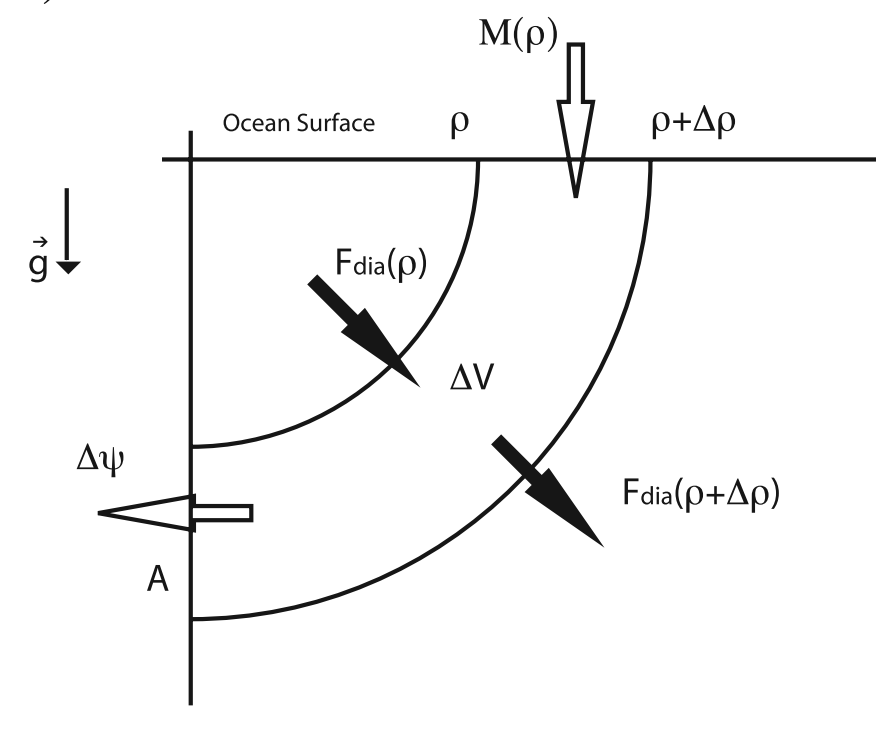

Figure 9. (a) The Aegean Sea and its three subbasins (black lines indicate the boundaries between these three subbasins); (b) budget for the water volume between two isopycnal surfaces $\rho$ and $\rho+\Delta \rho$.

[39] In the Southern subbasin, no new water mass is evidenced. The only change is observed for bottom waters with the apparition of a second branch in the $\theta-S$ diagram, saltier than the previous one during the last decade (Figures $10 \mathrm{e}$ and $10 \mathrm{f}$ ). The maximum density of this basin stays close to its previous value of $29.1 \mathrm{~kg} \mathrm{~m}^{-3}$.

[40] The increase in density of deep waters in the Aegean Sea is summarized in Figure 11 where the time evolution of the volume of waters denser than $\sigma_{\theta}=29.09 \mathrm{~kg} \mathrm{~m}^{-3}$ is displayed for the three subbasins. Indeed while the volume of waters denser than $29.09 \mathrm{~kg} \mathrm{~m}^{-3}$ remains constant, when excluding the seasonal cycle in the MED8-REF simulation, this volume sharply increases in the MED8-RANDOM simulation from the 39th year in the Central Aegean subbasin (Figure 11). This increase then occurs in the Northern subbasin and finally in the Southern subbasin where a maximum volume of $1.9 \times 10^{13} \mathrm{~m}^{3}$ is reached during year 44. This evolution of the volume of water denser than $29.09 \mathrm{~kg} \mathrm{~m}^{-3}$ in the different Aegean subbasins confirms that an anomalous event happens in this basin with an important increase in the volume of new water mass during the last decade. It also shows that the main water mass formation first occurs in the Central Aegean subbasin as expected from the water mass diagnosis described in section 4.2.

\subsection{Water Mass Budget in the Aegean Sea}

[41] In order to better understand the driving mechanisms of this event, a time-varying water mass budget is established. We apply the method introduced by Nurser et al. [1999] to the different control volumes shown in Figure 9. The time derivative of the control volume verifies the following equation:

$$
\frac{\partial \Delta V}{\partial t}=-\Delta \psi+F_{\text {dia }}(\rho)-F_{\text {dia }}(\rho+\Delta \rho)+M(\rho)
$$

where $\frac{\partial \Delta V}{\partial t}$ is the time derivative of the volume of water between $\rho$ and $\rho+\Delta \rho, \Delta \psi$ is the volume flux (advective flux), $F_{\text {dia }}$ is the diapycnal flux and $M(\rho)$ is the surface formation rate computed from $M(\rho) \Delta \rho=F(\rho+\Delta \rho)-F(\rho)$ with $F(\rho)$ given by equation (1).

[42] Prior to this analysis the choice of the relevant density layers has to be made. There is no obvious answer to this question since water mass properties significantly differ in the three subbasins. Three density layers are defined using an averaged salinity profile over the Mediterranean Sea: a surface layer, above the halocline, an intermediate layer, within the halocline, and a bottom layer, below the halocline. Density values that bound these three layers are then inferred from the averaged density profile that is superimposed on the averaged salinity profile. The following density ranges are thus obtained: $\sigma_{\theta}=$ [24. $\mathrm{kg} \mathrm{m}^{-3}, 28.84 \mathrm{~kg} \mathrm{~m}^{-3}$ ] for surface waters, $\sigma_{\theta}=$ [28.84 $\mathrm{kg} \mathrm{m}^{-3}, 29.09 \mathrm{~kg} \mathrm{~m}^{-3}$ ] for intermediate waters and $\sigma_{\theta}=\left[29.09 \mathrm{~kg} \mathrm{~m}^{-3}, 29.4 \mathrm{~kg} \mathrm{~m}^{-3}\right]$ for bottom waters. In the following we focus on the budget of the densest waters in the Central and Southern Aegean subbasins since the Northern Aegean subbasin plays a minor role due to weaker atmospheric fluxes.

[43] Volume budgets for the densest water mass class, of potential density larger than $\sigma_{\theta}=29.09 \mathrm{~kg} \mathrm{~m}^{-3}$, are displayed in Figure 12, thereafter referred to as deep water. For clarity the dominant terms, surface forcing and mixing term, and the secondary terms, time derivative of the volume and advective flux, are represented separately. The Central Aegean subbasin is the main site of formation for deep water with a net formation rate within the range 0.5 to $2 \mathrm{~Sv}$ (Figures 12c and 12d). This water mass formation is largely driven by the surface buoyancy flux as shown in Figure $12 \mathrm{~d}$, of an averaged value of $1.15 \mathrm{~Sv}$, both mixing and advective terms then contribute to the destruction of these deep waters (Figures 12c and 12d). The deep water cycle is characterized by a significant interannual variability 
a) RANDOM 25-35y

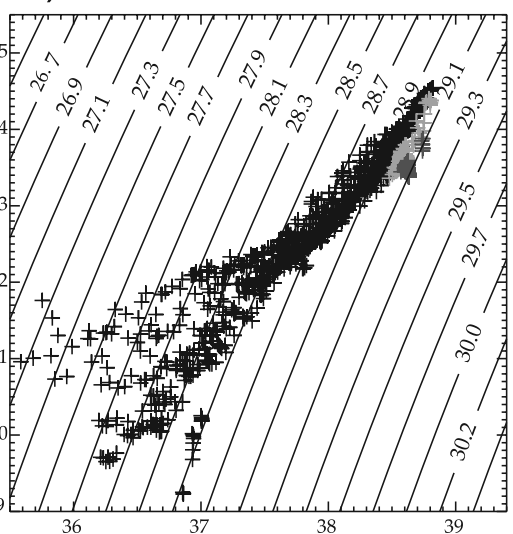

c)

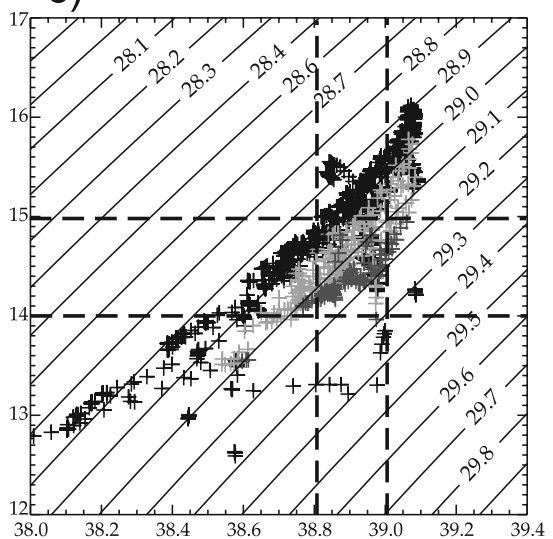

e)

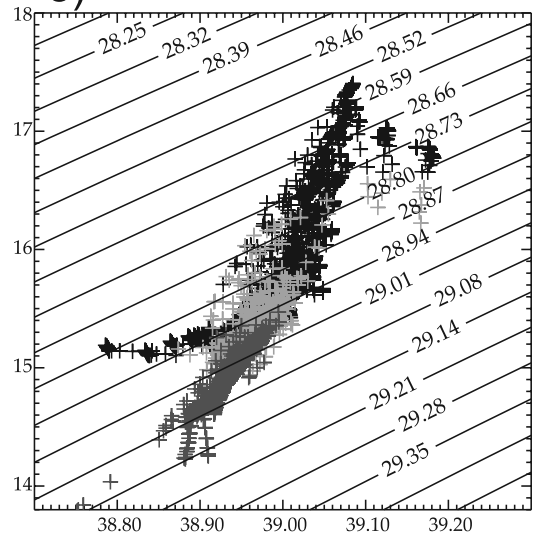

b) RANDOM 39-50y

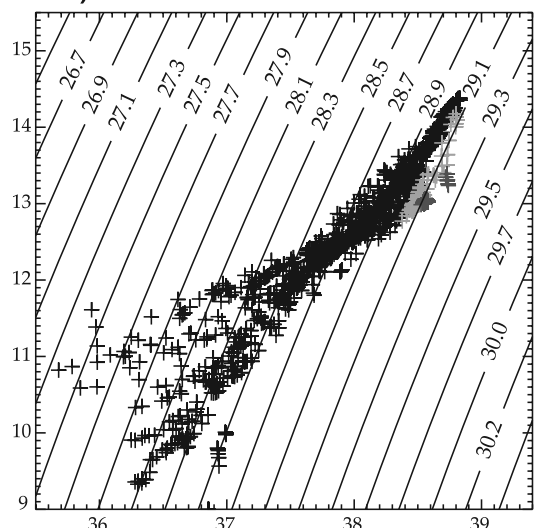

d)

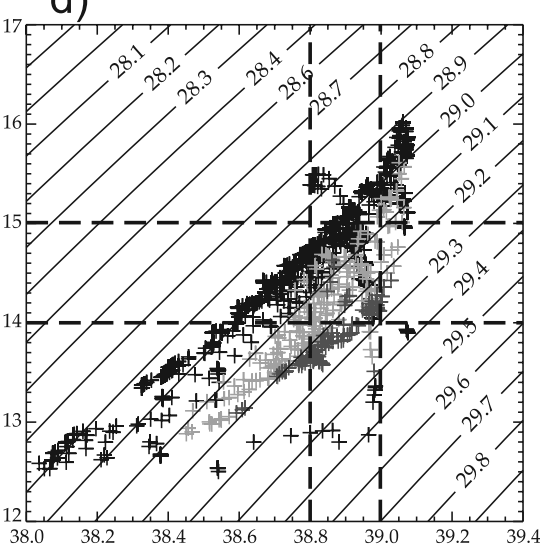

f)

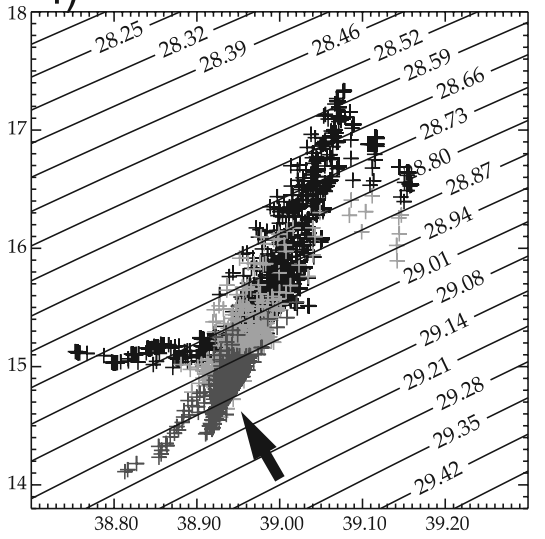

$\therefore 0-200 \mathrm{~m}$

$\therefore 200-400 \mathrm{~m}$

$\therefore 400-3000 \mathrm{~m}$

Figure 10. $\theta / \mathrm{S}$ diagrams in MED8-RANDOM. The first column (Figures 10a, 10c, and 10e) corresponds to winters for the period 25-35y, while the second column (Figures 10b, 10d, and 10f) corresponds to winters for the period 39-50y. The three subbasins are distinguished: the Northern Aegean in Figures 10a and 10b, the Central Aegean in Figures 10c and 10d, and the Southern Aegean in Figures $10 \mathrm{e}$ and $10 \mathrm{f}$.

with a period of weaker formation rates, from year 32 to year 38 of MED8-RANDOM, that can be correlated with positive heat flux anomalies (Figure 7) and weaker wind stress. In contrast periods of strong formation rates, typically of $1.5 \mathrm{~Sv}$, are observed, that can be correlated with negative heat flux anomalies (Figure 7). The building up of this anomalously dense water formation is revealed in the Southern Aegean subbasin (Figures 12a and 12b). This deep water is first noticed between year 27 and 32 in the Southern Aegean subbasin. The formation is fed both by the surface buoyancy flux (Figure 12b) and by the southward advective flux of deep waters originating from the Central 

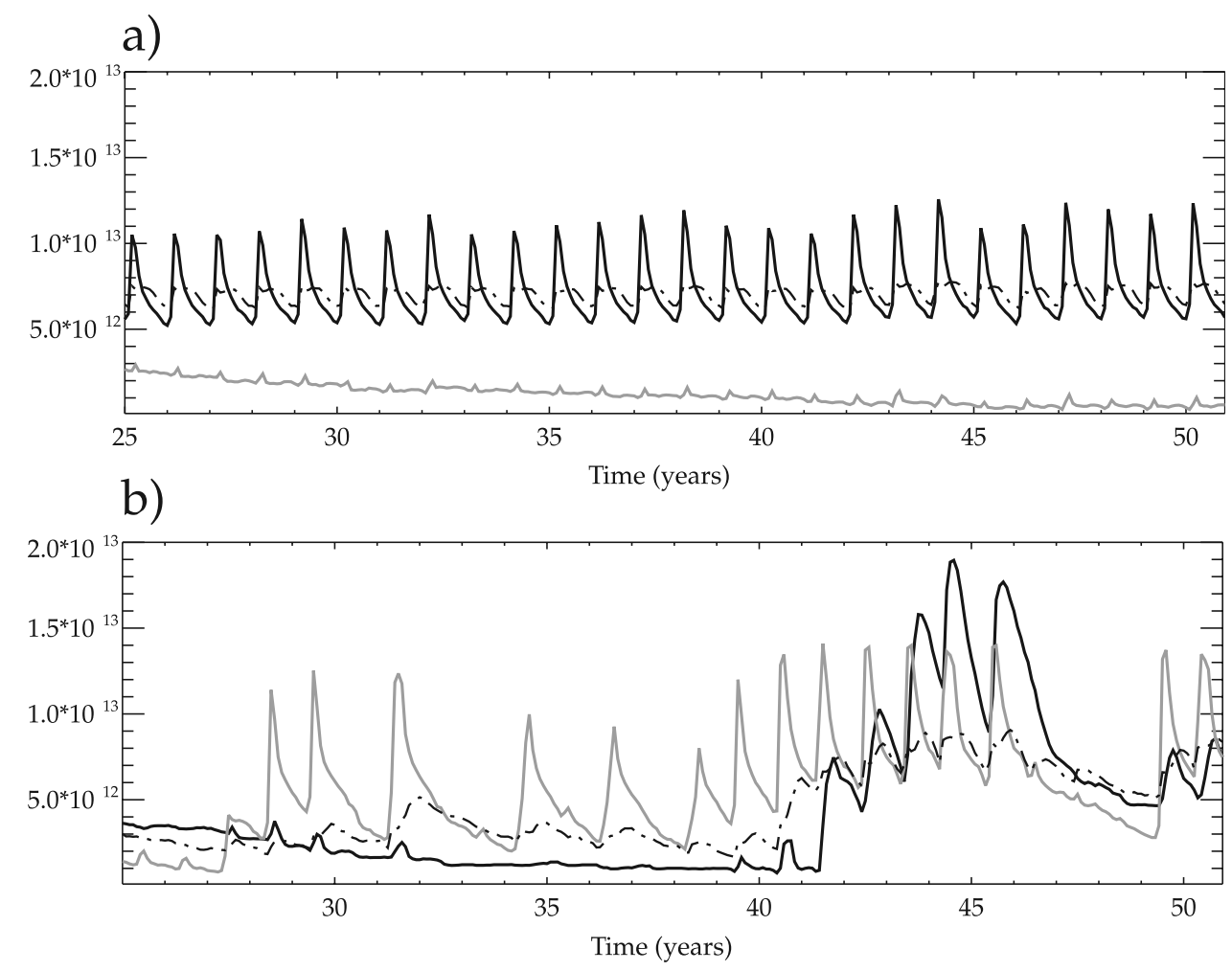

Figure 11. Time evolution of the volume of waters denser than $29.09 \sigma_{\theta}$ during the last 25 years of (a) MED8-REF and (b) MED8-RANDOM. The Southern Aegean subbasin corresponds to the thick black line, the Central Aegean subbasin to the thin grey line, and the Northern Aegean subbasin to the dotted dashed line.

subbasin (Figure 12a), with typical values of 0.05 to $0.5 \mathrm{~Sv}$. However, the net formation rate is weak, of the order of $0.3 \mathrm{~Sv}$ due to destructive mixing terms. Then a period without any deep water formation follows before the occurrence of the anomalous event. The net formation rate then increases from 0 up to $1 \mathrm{~Sv}$ over 2 years (from year 39 to 41). This formation is mainly driven by the surface buoyancy flux (Figure 13b), with a contribution up to $7 \mathrm{~Sv}$, and with a minor contribution of the southward advective flux (Figure 13a), of the order of $0.7 \mathrm{~Sv}$. Then, as in the Central subbasin, mixing processes lead to the conversion of part of this deep water into intermediate waters. The atmospheric forcing thus plays a major role in the onset of this anomalous event.

[44] The overall budget involving intermediate and deep waters in the Central and Southern Aegean subbasins is displayed in Figure 13. A schematic representation using boxes is chosen in order to enhance the water exchanges between the different compartments. Two particular years of MED8-RANDOM are displayed: the first one, year 25, prior to the anomalous event, the second one, year 45, during the anomalous event.

[45] In the "traditional" situation such as that of year 25, the main water mass transformations occur in the intermediate layer (Figure 13a). These are formed through the direct influence of the atmospheric forcing, with a formation rate twice larger in the Southern subbasin than in the Central one, $0.35 \mathrm{~Sv}$ compared to $0.17 \mathrm{~Sv}$. Most of the intermediate waters produced in the Central subbasin are then advected toward the Southern subbasin, with an advective flux of $0.14 \mathrm{~Sv}$. In contrast intermediate waters in the Southern subbasin are mainly destroyed through mixing processes, with a value of $0.51 \mathrm{~Sv}$ for this term.

[46] During periods of anomalous deep water formation, the budget strongly differs (Figure 13b). The atmospheric forcing thus leads to strong deep water formation, with a formation rate of the order of $0.35 \mathrm{~Sv}$ in the two subbasins. In the Central subbasin the formation of deep water is almost balanced by a southward advection, with a value of $0.25 \mathrm{~Sv}$, and mixing processes that feed overlying intermediate waters, with a value of $0.04 \mathrm{~Sv}$. In the Southern subbasin the advection of deep waters originating from the Central subbasin contributes significantly to the increase in deep water volume with a value of $0.25 \mathrm{~Sv}$ that is of the same order as the atmospheric formation rate of $0.35 \mathrm{~Sv}$. Mixing processes play a major role in the destruction of these deep waters with a contribution of 0.44 Sv. Interestingly the export of these deep waters toward the Levantine basin is not negligible with a value of $0.11 \mathrm{~Sv}$. Two striking changes for intermediate waters are observed. Firstly, in contrast to the "traditional" period, the atmospheric forcing leads to the destruction of intermediate waters in the Central subbasin in late spring and summer with a value of $0.17 \mathrm{~Sv}$. Secondly, the mass transport between the two subbasins is reversed, with a net inflow from the South, and there is a significant inflow of intermediate waters from the Levantine 

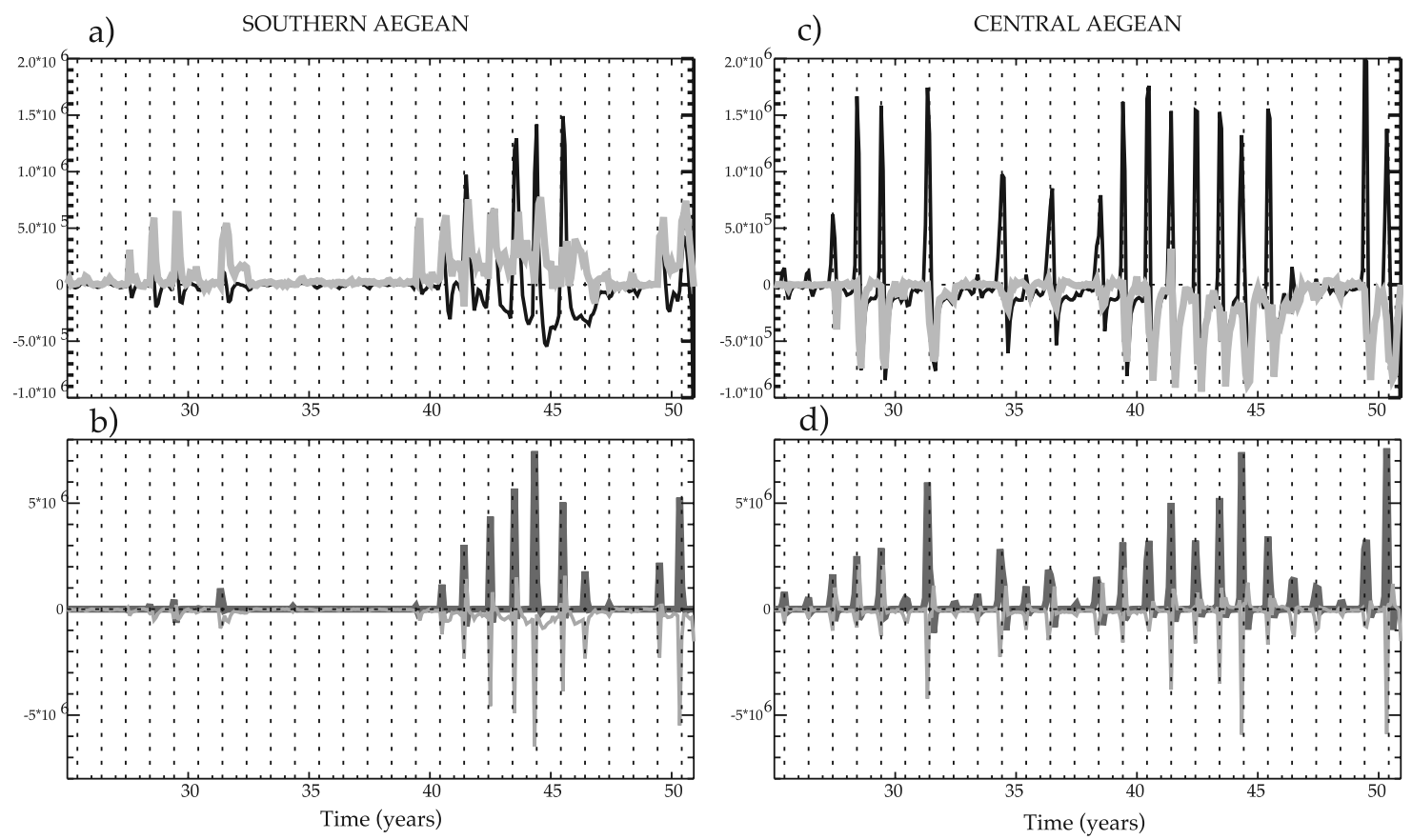

Figure 12. Dense water mass budget in $\mathrm{m}^{3} \mathrm{~s}^{-1}$ during the last 25 years of MED8-RANDOM in the Southern and Central Aegean subbasins, for density values larger than $29.09 \sigma_{\theta}$ : (a) time derivative of the water volume, $\Delta V$, (black curve), and advective flux, $-\Delta \psi$, (thick grey curve) in the Southern Aegean subbasin; (c) time derivative of the water volume, $\Delta V$, (black curve) and advective flux, $-\Delta \psi$, (thick grey curve) in the Central Aegean subbasin; (b) surface buoyancy flux (dark grey curve) and mixing term (light grey curve) in the Southern Aegean subbasin; (d) surface buoyancy flux (dark grey curve) and mixing term (light grey curve) in the Central Aegean subbasin.

basin. Thus exchanges with the Levantine basin, that were negligible during the traditional period, are increased during the anomalous event.

[47] In summary extreme atmospheric conditions endured in the Aegean Sea during the last 10 years of MED8RANDOM, led to strong modifications in water formation and exchanges through the different reservoirs. In particular this intensified forcing drives the formation of an anomalously dense water in winter that replaces the traditional formation of intermediate waters. As a consequence, the balance for these intermediate waters strongly differs, especially in the Central subbasin where these waters are destroyed under the action of the atmospheric forcing. Moreover, the circulation scheme between the two subbasins is reversed. More importantly advective fluxes to the Levantine basin become nonnegligible for a few years during the anomalous event with a maximum in year 45 . Thus part of these dense waters are exported outward from the Aegean Sea. However, this export of deep waters remains weak during the other years which explains why the impact of the anomalous event is localized spatially.

\section{Discussion}

[48] In this study, we focused on the sensitivity of the Aegean Sea to an interannual atmospheric variability using an eddy permitting ocean circulation model, of $1 / 8^{\circ}$ resolution. First the sensitivity of the Aegean Sea was tested under an atmospheric forcing presenting a strong interannual variability with a succession of cold winters. In this way the two responses of the model as well as the possible occurrence of anomalous events such as the EMT were addressed. Furthermore, this study can also be viewed as the first part of the characterization of the THC variability under different climatic conditions.

[49] A 50-year random forcing was constructed using the presently available high-resolution ECMWF outputs. The last period of the forcing was characterized by a cold bias that was propitious to the onset of a transient in the Aegean Sea. During the last ten years of the simulation, successive cold winters were encountered over the Aegean Sea with net heat loss larger than $400 \mathrm{~W} \mathrm{~m}^{-2}$ for 6 over 10 years. We focused our analysis on the anomalous event that occurred in the Aegean Sea during that period. Striking changes in water mass were observed with the generation of an anomalously dense water mass in place of intermediate waters. This cooling was driven by a particularly intense surface buoyancy flux whose values were about twice higher than typical values. This deep water participated in the formation of intermediate water through mixing processes. Interestingly advective fluxes of bottom waters outward from the Aegean Sea were very weak, except for a few years during the anomalous event, which explains why the impact of this event remained local.

[50] It is interesting to compare this anomalous event with the EMT, which also results from strong atmospheric cooling. Indeed the atmospheric forcing over the Aegean Sea was characterized by particularly cold winters in 1987, 

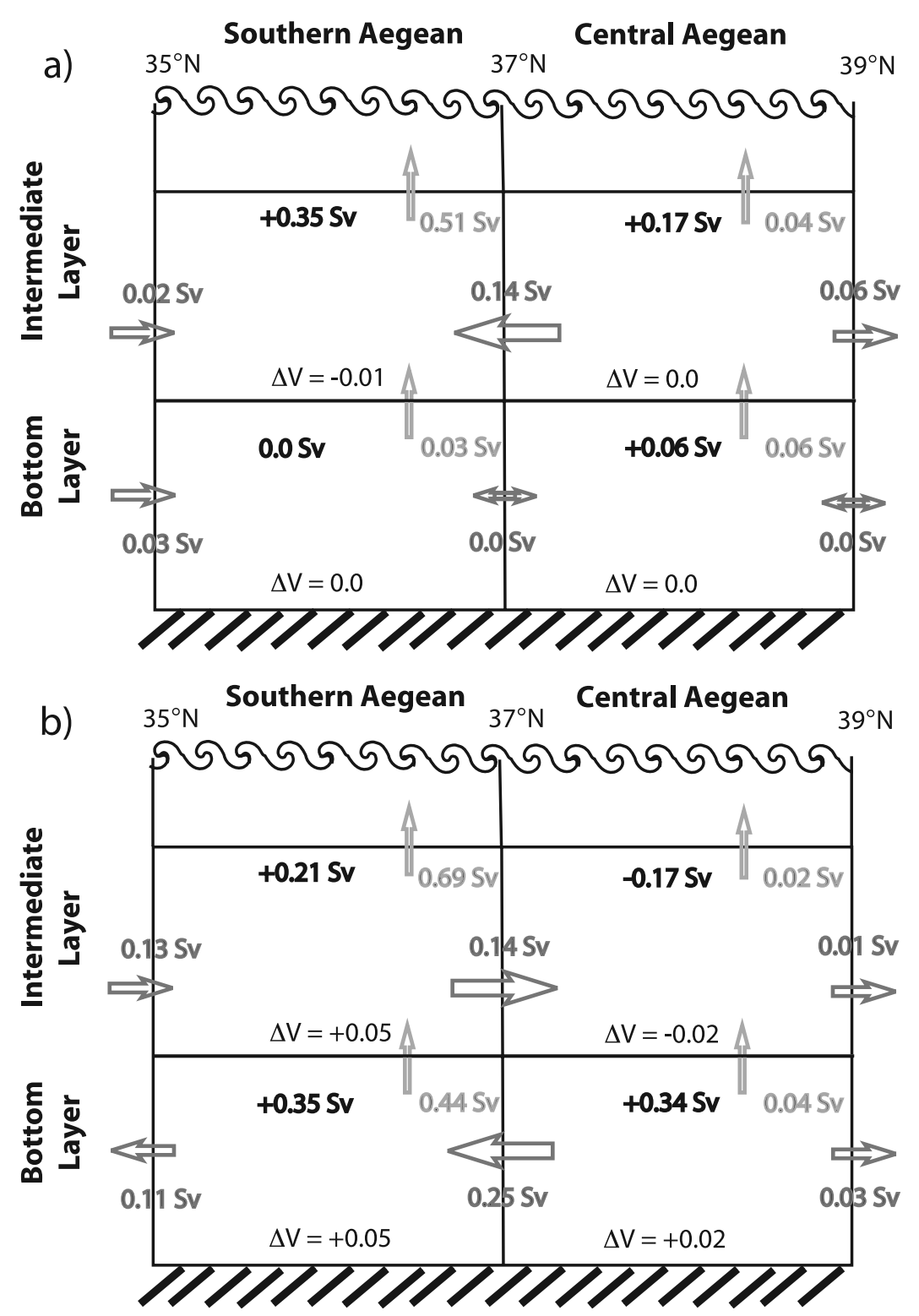

Figure 13. Budgets of intermediate and deep water volumes in the Southern and Central Aegean subbasins for MED8-RANDOM: (a) year 25, before the anomalous event; (b) year 45 during the anomalous event. $\Delta V$ denotes the net volume variation in thin black, the "atmospheric" formation rate is represented in thick black, mixing terms are displayed in light grey with vertical arrows, and advective fluxes in dark grey with horizontal arrows.

1992, and 1993 [Stratford and Haines, 2002]. Besides, a strong positive anomaly in the salinity budget of the Aegean Sea played an important role in the onset of the EMT as shown by Theocharis et al. [1999]. This anomaly resulted from a reduction in the Black Sea discharge combined with an increase in evaporation during this period. The main formation sites of deep waters were located in the Central and the Northern Aegean subbasins as described by Nittis et al. [2003]. These striking changes then led to an increasing transport of dense waters into the Levantine basin. Tsimplis et al. [1999] showed that the transport through the Strait of Karpathos increased from $0.2 \mathrm{~Sv}$ to $1 \mathrm{~Sv}$ and Lascaratos et al. [1999] gave evidence of a $29.3 \mathrm{~kg} \mathrm{~m}^{-3}$ water mass flowing through the straits of the Cretan Arc in 1995. Another important point was the role of the general circu- lation in the EMT. Indeed, observations showed a modification in the eastern circulation especially in the Ionian basin and in the Levantine basin where some anticyclonic gyres blocked the Atlantic Water entering the Levantine basin while other gyres constrained the LIW to flow into the Aegean Sea [Malanotte-Rizzoli et al., 1999].

[51] In MED8-RANDOM, the onset of the anomalous event resulted from the occurrence of the cold winter 2003 during the last half of the simulation (years 40, 42, 43, and 45). The winter 2003 is characterized by strong heat loss and strong wind stress. The EMP flux (evaporation minus precipitation minus runoff) does not present any peculiar change. The atmospheric forcing that occurred during the last period of MED8-RANDOM may thus simulate the atmospheric forcing that occurred during the EMT accord- 
ing to Josey [2003]. Our anomalous event however significantly differs from the EMT. Indeed in MED8-RANDOM the export of deep waters out of the Aegean Sea remained weak except for a few years and an almost closed circulation cell involving intermediate and deep waters was established between the Central and Southern subbasins. The impact of this event remained localized spatially as opposed to the EMT. Another factor that could explain this difference is that the density of the water formed by the model in the Aegean Sea did not exceed $\sigma_{\theta}=29.3 \mathrm{~kg} \mathrm{~m}^{-3}$ in the Central subbasin and $\sigma_{\theta}=29.1 \mathrm{~kg} \mathrm{~m}^{-3}$ in the Southern subbasin in contrast with the EMT observations. The fact that the variability in the Black Sea discharge is not taken into account in the model could also be an explanation. Another point is the absence of real change in the general circulation of the eastern Mediterranean Sea, except for a slight intensification of the circulation of the Rhodes Gyre.

[52] We showed that an EMT like event might occur again in the next few years. What will be the new characteristics of the hydrology of the Aegean Sea after a second EMT is an open question that is beyond the scope of this study. A difficulty of this study is to correctly model the export of deep Aegean waters formed during the anomalous event into the Ionian and the Levantine basins and consequently the evolution of the hydrology of the Aegean Sea at depth. The differences observed with the EMT revealed as well the variety of events that could occur and the very different consequences that could result. A major issue of this study is that the variability of the Mediterranean circulation is more sensitive to the atmospheric forcing than to some internal variability of the basin. The next stage under present investigation is the characterization of such event under climate change scenarios.

[53] Acknowledgments. We acknowledge L. Li for stimulating discussions. Financial support was provided by the French national program GICC (Gestion et Impact du Changement Climatique). We are grateful to the French Mercator project http://www.mercator-ocean.fr) which provided the atmospheric forcing from the European Centre for Medium-Range Weather Forecasts (ECMWF). Numerical simulations were performed on the NEC SX-5 of the Institut du développement et des Ressources en Informatique Scientifique (IDRIS) from the Centre National de la Recherche Scientifique (CNRS).

\section{References}

Artegiani, A., D. Bregant, E. Paschini, N. Pinardi, F. Raicich, and A. Russo (1997), The Adriatic Sea general circulation. Part I: Air-Sea interactions and Water mass Structure, J. Phys. Oceanogr., 27, 1492-1514.

Barnier, B., L. Siefrid, and P. Marchesiello (1995), Thermal forcing for a global ocean circulation model using a three-year climatology of ECMWF analyses, J. Mar. Syst., 6, 363-380.

Béranger, K., L. Mortier, L. Gervasio, G. P. Gasparini, M. Astraldi, and M. Crépon (2004), The surface circulation dynamics of the Sicily strait: a comprehensive study from the observations to the models, the role of the topography, Deep Sea Res., Part II, 51, 411-440.

Béthoux, J. P. (1979), Budgets of the Mediterranean Sea. Their dependance on the local climate and on the characteristics of the Atlantic waters, Oceanol. Acta, 2, 157-163.

Blanke, B., and P. Delecluse (1993), Variability of the tropical Atlantic Ocean simulated by a general circulation model with two different mixed layer physic, J. Phys. Oceanogr., 23, 1363-1388.

Boukthir, M., and B. Barnier (2000), Seasonal and inter-annual variations in the surface freshwater flux in the Mediterranean Sea from the ECMWF re-analysis project, J. Mar. Syst., 24, 343-354.

Demirov, E., and N. Pinardi (2002), Simulation of the Mediterranean Sea circulation from 1979 to 1993: Part I the Interannual variability, J. Mar. Syst., 33-34, 23-50.

Drillet, Y., K. Béranger, M. Brémond, F. Gaillard, C. Le Provost, and S. Theetten (2000), Expérimentation PAM, Tech. Rep. MERCATOR Proj.
Garrett, C., R. Outerbridge, and K. Thompson (1993), Interannual variability in Mediterranean Heat and Buoyancy fluxes, J. Clim., 6, 900-910. Gertman, I. F., I. M. Ovchinnikov, and Yu. I. Popov (1994), Deep convection in the Eastern basin of the Mediterranean Sea, Oceanology, 34, 1924.

Horton, C., J. Kerling, G. Athey, J. Schmitz, and M. Clifford (1994), Airborne expendable bathythermograph surveys of the eastern Mediterranean, J. Geophys. Res., 99, 9891-9905.

Jerlov, N. G. (1968), Optical Oceanography, 194 pp., Elsevier, New York. Josey, S. A. (2003), Changes in the heat and freshwater forcing of the eastern Mediterranean and their influence on deep water formation, J. Geophys. Res., 108(C7), 3237, doi:10.1029/2003JC001778.

Klein, B., W. Roether, B. B. Manca, D. Bregant, V. Beitzel, V. Kovacevic, and A. Luchetta (1999), The large deep water transient in the Eastern Mediterranean, Deep Sea Res., Part I, 46, 371-414.

Lascaratos, A., W. Roether, K. Nittis, and B. Klein (1999), Recent changes in deep water formation and spreading in the eastern Mediterranean Sea: a review, Prog. Oceanogr., 44, 5-36.

Lévy, M., A. Estublier, and G. Madec (2001), Choice of an advection scheme for biogeochemical models, Geophys. Res. Lett., 28, 37253728 .

MacDonald, A., J. Candela, and H. L. Bryden (1994), An estimate of the net heat transport through the strait of Gibraltar, in Seasonal and Interannual Variability of the Western Mediterranean Sea, Coastal Estuarine Stud., vol. 46, edited by P. E. La Violette, pp. 13-32, AGU, Washington, D. C.

Madec, G., P. Delecluse, M. Imbard, and C. Lévy (1998), OPA8.1, Ocean General Circulation Model, Reference manual, Note du Pôle de modélisation de l'IPSL. (Available at http://www.lodyc.jussieu.fr/opa)

Malanotte-Rizzoli, P., B. B. Manca, M. Ribera d'Alcala, A. Theocharis, S. Brenner, G. Budillon, and E. Ozsoy (1999), The Eastern Mediterranean in the $80 \mathrm{~s}$ and in the 90s: the big transition in the intermediate and deep circulations, Dyn. Atmos. Oceans, 29, 365-395.

MEDAR/MEDATLAS Group (2002), MEDAR/MEDATLAS 2002 Database. Cruise inventory, observed and analysed data of temperature and bio-chemical parameters [CD-ROM].

MEDOC Group (1970), Observation of formation of deep water in the Mediterranean Sea, Nature, 227, 1037-1040.

Mertens, C., and F. Schott (1998), Interannual Variability of Deep-Water Formation in the Northwestern Mediterranean, J. Phys. Oceanogr., 28, $1410-1424$

Myers, P. G., K. Haines, and S. Josey (1998), On the importance of the choice of wind stress forcing to the modeling of the Mediterranean Sea circulation, J. Geophys. Res., 103, 15,729-15,749.

Nittis, K., A. Lascaratos, and A. Theocharis (2003), Dense water formation in the Aegean Sea: Numerical simulations during the Eastern Mediterranean Transient, J. Geophys. Res., 108(C9), 8120, doi:10.1029/ 2002JC001352.

Nurser, A. J. G., R. Marsh, and R. G. Williams (1999), Diagnosing Water Mass Formation from Air-Sea Fluxes and Surface Mixing, J. Phys. Oceanogr., 29, 1468-1487.

Pacanowski, R. C., and A. Gnanadesikan (1998), Transient Response in a Z-level ocean model that resolves Topography with Partial Cells, Mon. Weather Rev., 126, 3248-3270.

Reynaud, T., P. Legrand, H. Mercier, and B. Barnier (1998), A new analysis of hydrographic data in the Atlantic and its application to inverse modelling study, Int. Woce Newsl., 32, 29-31.

Reynolds, R. W. (1988), A real-time global sea surface temperature analysis, J. Clim., 1, 75-86.

Roether, W., B. Manca, B. Klein, D. Bregant, D. Georgopoulos, V. Beitzel, V. Kovacevic, and A. Luchetta (1996), Recent changes in the Eastern Mediterranean Deep Waters, Science, 271, 333-335.

Roether, W., B. Klein, V. Beitzel, and B. B. Manca (1998), Property distributions and transient-tracer ages in Levantine Intermediate Water in the Eastern Mediterranean, J. Mar. Syst., 18, 71-87.

Siefridt, L., Y. Drillet, R. Bourdalle-Badie, K. Béranger, C. Talatier, and E. Greiner (2002), Mise en oeuvre du modéle Mercator: haute résolution sur l'Atlantique Nord et la Méditerranée, Newsl. MERCATOR.

Stratford, K., and K. Haines (2002), Modelling changes in Mediterranean Thermohaline circulation 1987-1995, J. Mar. Syst., 33-34, 51-62.

Stratford, K., and R. G. Williams (1997), A tracer study of the formation, dispersal, and renewal of Levantine Intermediate Water, J. Geophys. Res., $102,12,539-12,549$

Theocharis, A., K. Nittis, H. Kontoyiannis, E. Papageorgiou, and E. Balopoulos (1999), Climatic changes in the Aegean Sea influence the Eastern Mediterranean thermohaline circulation (1986-1997), Geophys. Res. Lett., 26, 1617-1620.

Theocharis, A., B. Klein, K. Nittis, and W. Roether (2002), Evolution of the Eastern Mediterranean Transient (1997-1999), J. Mar. Syst., 33-34, $91-116$. 
Tsimplis, M. N., A. F. Velegrakis, P. Drakopoulos, A. Theocharis, and M. B. Collins (1999), Cretan Deep Water outflow into the Eastern Mediterranean, Prog. Oceanogr., 44, 531-551.

Tziperman, E., and K. Speer (1994), A study of water mass transformation in the Mediterranean Sea: analysis of climatological data and a simple three-box model, Dyn. Atmos. Oceans, 21, 53-82.

Vilibic, I., and M. Orlic (2002), Adriatic water masses, their rates of formation and transport through the Otranto Strait, Deep Sea Res., Part I, $49,1321-1340$

Walin, G. (1982), On the relation between sea-surface heat flow and the thermal circulation in the ocean, Tellus, 34, 187-195.
Wu, P., K. Haines, and N. Pinardi (2000), Toward the understanding of deep-water Renewal in the Eastern Mediterranean, J. Phys. Oceanogr. $30,443-458$

K. Béranger, Unité de Mécanique, Ecole Nationale Supérieure de Techniques Avancées, 75739 Paris, France.

P. Bouruet-Aubertot, A. Bozec, and M. Crépon, Laboratoire d'Océanographie et de Climatologie -Expérimentation et Approches Numériques-, LOCEAN/IPSL/UPMC (previously LODYC), 75252 Paris, France. (alb@ lodyc.jussieu.fr) 